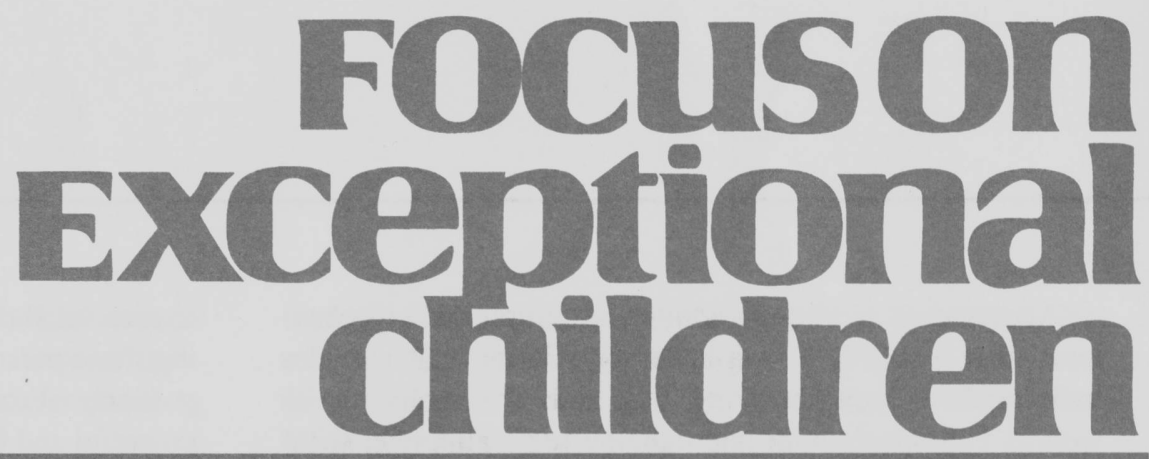

\title{
Vocational and Transition Interventions for Adolescents and Young Adults with Emotional or Behavioral Disorders
}

\author{
Michael Bullis and Douglas Cheney
}

The Transition Initiative was initiated in the early 1980s, with the goal of improving the post-school work experiences of all students with disabilities (Will, 1984). From a strict focus on employment instruction and outcomes, the transition effort expanded to include a broader-based emphasis on community adjustment, of which employment was but one of several possible goals and outcomes (Knowlton \& Clark, 1987; Halpern, 1985). This point is evident in the 1992 Amendments to the Individuals with Disabilities Education Act, which defined transition services in the following way.

\begin{abstract}
Transition services means a coordinated set of activities for a student, designed within an outcome-oriented process, that promotes movement from school to post-school activities, including post-secondary education, vocational training, integrated employment (including supported employment), continuing and adult education, adult services, independent living, or community participation. The coordinated set of activities must be based on the individual student's needs, taking into account the student's preferences and interests, and must include instruction, community experiences, the development of employment and other post-school adult living objectives, and, if appropriate, acquisition of daily living skills and functional vocational evaluation.
\end{abstract}

Through this initiative, hundreds of projects have been conducted to address the transition needs of students in special education, both to study how best to provide transition services and to describe the transition experiences of students with disabilities in community settings so as to provide a baseline of results from which to judge transition achievement. Probably the best known example of this latter group of projects was the National Longitudinal Transition Study (DeStefano \& Wagner, 1992; Wagner, 1992), which (a) included a nationally representative sample of special education students and (b) was conducted prospectively to describe the school-leaving and community-adjustment experiences of students for up to 4 years after leaving school (Valdes, Williamson, \& Wagner, 1990). Perhaps the most surprising, or at least the most salient, finding from that project was how poorly students with emotional disabilities performed on nearly every transition outcome variable that was studied in relation to their peers with other types of disabilities and in relation to standards from other databases on peers without disabilities (Marder, 1992a; Valdes, Williamson, \& Wagner, 1990).

In addition to displaying less positive transition achievement as compared to peers with other disabilities, this population performed antisocial acts at high rates (Marder, 1992a; Wagner, 1992a). The importance of these findings has been underscored in recent years with the rise in violence in the adolescent age group (Koop \& Lundberg, 1992) and increased concern by the general public about school safety and juvenile crime (Elam, Rose, \& Gallup, 1994).

Michael Bullis is affiliated with the University of Oregon. Douglas Cheney is affiliated with the University of Washington. 
Adolescents and young adults with emotional or behavioral disorders $(\mathrm{EBD})^{1}-\mathrm{a}$ broad population that includes individuals with externalizing (e.g., antisocial) behaviors as well as individuals with internalizing (e.g., affective, withdrawn) behaviors-pose unique and difficult servicedelivery challenges to educational and social service staffs.

Adolescents whom the public schools do not formally label as ED, but who may present patterns of antisocial behaviors (criminality, alcohol and substance abuse, aberrant sexual behaviors, school failure) or who receive a psychiatric label from a community-based agency pose thorny service delivery challenges as they typically are not afforded special education or transition services in any consistent and effective manner.

A reality for adolescents with EBD is that few continue their education after leaving high school and most do not receive services from community-based social service agencies, entering what truly is an unwelcoming and "cold world" as adults in society. Vocational and transition services offered to adolescents and young adults with EBD during and after the secondary years are apt to be the last set of coordinated educational and social services they are likely

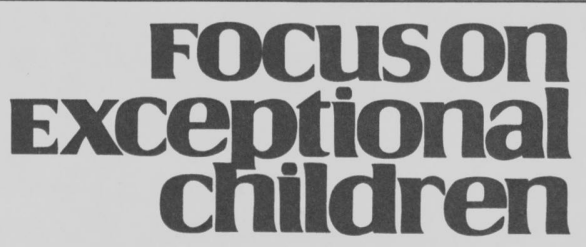

ISSN 0015-511X FOCUS ON EXCEPTIONAL CHILDREN (USPS 203-360) is published monthly except June, July, and August as a service to teachers, special educators, curriculum specialists, administrators, and those concerned with the special education of exceptional children. This publication is annotated and indexed by the ERIC Clearinghouse on Handicapped and Gifted children for publication in the monthly Current Index to Journals in Education (CIJE) and the quarterly index, Exceptional Children Education Resources (ECER). The full text of Focus on Exceptional Children is also available in the electronic versions of the Education Index. It is also available in microfilm from Xerox University Microfilms, Ann Arbor, MI. Subscription rates: Individual, \$30 per year; institutions, $\$ 40$ per year. Copyright (C) 1999, Love Publishing Company. All rights reserved. Reproduction in whole or part without written permission is prohibited. Printed in the United States of America. Periodicals postage is paid at Denver, Colorado. POSTMASTER: Send address changes to:

\section{Love Publishing Company \\ Executive and Editorial Office P.O. Box 22353 \\ Denver, Colorado 80222 \\ Telephone (303) 221-7333}

Edward L. Meyen

University of Kansas
Glenn A. Vergason Georgia State University
Richard J. Whelan

University of Kansas Medical Center to receive. If these services are to have any chance of affecting these persons in a positive manner, and improving their post-school transition outcomes, they must be offered in as powerful and focused a manner as possible. These programs are especially important because adolescence can be an efficacious time for interventions. The impending entry into adulthood may initiate a desire to learn that was not present in earlier grades (Albee, 1982; Hobbs \& Robinson, 1982; Kazdin, 1993).

Moreover, vocational training and competitive work placements offered during high school can have a positive effect on school completion (Thornton \& Zigmond, 1987; Thornton \& Zigmond, 1988; Weber, 1987), post-school success at work (Hasazi, Gordon, \& Roe, 1985), and personal adjustment in community settings (Garrett, 1985; Kazdin, 1987a, 1987b; Massimo \& Shore, 1963; Shore, Massimo, \& Mack, 1965). Most general vocational and transition programs for students with disabilities, however, either do not serve, or have minimal success with, this population, suggesting that an alternative form of service provision is necessary to address the unique needs of this population (Bullis \& Fredericks, in press; Bullis \& Gaylord-Ross, 1991).

The purpose of this article is to describe the way-at least in our view-in which these services should be provided to adolescents and young adults with EBD. These opinions and suggestions are based on the available professional literature, as well as our experiences in administering and directing federally funded model demonstration programs for this population. We begin by discussing the population and its transition outcomes. Following this, we briefly describe the vocational and transition programs we have administered and discuss key service delivery components of those programs. We conclude by making suggestions for future development and work in this important area.

\section{POPULATION AND TRANSITION OUTCOMES}

Perhaps the most prominent characteristic of persons with EBD is poor social skills. In particular, for adolescents and young adults with EBD in transition, these social skill deficits are evident in work (Bullis, Nishioka-Evans, Fredericks, \& Davis, 1993) and community living (Bullis, Bull, Johnson, \& Johnson, 1994) settings. Beyond this global feature, and in line with the need to plan effective services, one must ask what happens to these students in their transition from school to early adult life. Overall, and as we will profile in

\footnotetext{
'In this article we use the term emotional disturbance (ED) to refer to persons who have been formally labeled through the special education process. We use the term emotional or behavioral disorders (EBD) to describe the larger groups of adolescents who are formally labeled as having a special education disability and those persons who have the potential to be so labeled but for some reason do not carry an official disability label.
} 
this section, the employment, education, and social experiences of this population are far poorer than those of their peers with other types of disabilities and as compared to peers without disabilities.

Complicating a clear summary of these data, however, is the way in which the concept of "disability" is attached, or not attached, to emotional or behavioral disorders. Most of the transition outcome data that have been gathered have included persons who have gone through a formal special education assessment and labeling process and who have met the criteria as having a special education disability and having received special services because of that condition. This assumes great relevance, as a number of leading professionals believe that many adolescents who could be categorized as having an emotional disturbance are not so labeled (e.g., Forness \& Kavale, 1993; Walker, Colvin \& Ramsey, 1995). It follows that the findings may not reflect the transition experiences of peers who are not so labeled but who present significant emotional or behavioral disorders in the context of the public schools and community social service agencies. Accordingly, to provide a framework from which to interpret these findings, as well as to understand the service delivery demands of this population, we first provide a brief summary of the parameters and characteristics of this population.

\section{Overview of the Population}

For years, professionals in special education have bemoaned the lack of precision in the way in which disability labels are assigned to students with special learning needs (Hallahan \& Kauffman, 1977). The exact criteria applied to the category of "emotional disturbance 2 " has been particularly controversial (Kauffman, 1988), as has the meaning that can be affixed to the label to describe these individuals precisely for research or intervention purposes (Kavale, Forness, \& Alper, 1986; MacMillan \& Kavale, 1986).

Currently, just less than $1 \%$ of the school population is judged to be ED and receive special education services because of that disability. The general sentiment, however, is that between $2 \%$ and $4 \%$ of the total school population could receive such a label (Bullis \& Walker, 1995; Kauffman, 1988), suggesting that at best only half of the total number of students who could receive special education services for this disorder will be so served.

We believe the discrepancy between the apparent prevalence of these conditions and the labeling has two root causes. First, confusion exists over just what constitutes ED (Kelley, 1986; Walker \& Bullis, 1991). Specifically, should these people be judged as having a disability that demands special services and interventions, or do these behaviors simply reflect a volitional choice that is outside the pale and tolerance of general society and that should be punished rather than treated (cf., Council for Children With Behavioral Disorders, 1989; Forness, \& Knitzer, 1992; Maag \& Howell, 1991; National School Boards Association, 1993; Nelson, Center, Rutherford, \& Walker, 1991)?

Second, policy makers are generally reluctant to assign a disability label because of concern for (a) the economic implications of increasing the special education census (Kozleski, Cessna, Bechard, \& Borock, 1993) and (b) affording special education protections to students who present antisocial behaviors (National School Boards Association, 1993).

Social policy concerns notwithstanding, an extensive research base on child and adolescent emotional disturbances suggests two distinct patterns of problematic behaviors evident in the school-age group: "internalizing" and "externalizing" dimensions.

The "broad-band" grouping designated as Internalizing
mainly involves problems within the self, such as unhappi-
ness and fears. The broad-band grouping designated as
Externalizing, by contrast, mainly involves conflicts with
others, such as aggressive, delinquent, and overactive
behavior. (Achenbach \& McConaughy, 1987, p. 33)

Internalizing disorders usually are directed inwardly toward the individual himself or herself, usually represented by problems such as social withdrawal/isolation, low selfconcept, phobias, and depression. In contrast, externalizing disorders are represented by maladaptive behavior that is directed outwardly toward the external social environment or others (e.g., verbal and physical aggression) (Achenbach, 1966, 1990).

The vast majority of emotional disturbances that children and adolescents display is of an externalizing nature (Kauffman, 1988; Walker \& Bullis 1991). The Council for Children with Behavioral Disorders (1989) has gone on record that students who display externalizing types of behaviors (including those with antisocial behaviors) should be considered for special education services.

\begin{abstract}
It is the position of the Executive Committee of the Council for Children with Behavioral Disorders that conduct disorder is one of several behavior patterns subsumed under behavioral disorder/emotional disturbance. The exclusionary interpretation represents a serious error that threatens to have grave consequences for children with behavioral disorders. Examination of both the educational and psychological assessment literature leads to the inescapable conclusion that we lack both the definitional criteria and the assessment technology for making valid discriminations between social maladjustment and emotional disturbance.
\end{abstract}

The Council for Exceptional Children (1998) has gone on record as supporting a change in the definition of ED that is consistent with the above position.

By adolescence, the externalizing dimension typically evolves into four distinct, yet interrelated, behavioral clusters - criminal behavior, school failure, substance abuse, 
and aberrant sexual behaviors-that are called "antisocial" or "at-risk" (Donovan \& Jessor 1985; Dryfoos, 1990). Current estimates suggest that roughly $25 \%$ of all adolescents in the United States are at-risk to engage in one of these four sets of behaviors, $10 \%$ will engage in two of the sets of behaviors, and about 5\% will engage in all four sets of behaviors. This latter, most extreme, group of adolescents are the ones who pose the greatest concern to educators, social service professionals, and the general public; especially in light of the upsurge of antisocial behaviors that adolescents in the United States have exhibited over the past decade (Patterson, Reid, \& Dishion 1992; Quay, 1986). This segment of the population presents disorders that are highly durable and resistant to change, despite the most intensive interventions (Kazdin, 1987a, 1987b; Wolf, Braukmann, \& Ramp, 1987).

Although a large proportion of the adolescents who display extreme and multifaceted types of antisocial behaviors should and could be assigned a special education label, many are not (Rutherford, Bullis, Wheeler Anderson, \& Griller, in press). This fact carries implications for developing service-delivery programs for this population and for considering research on transition outcomes for this group.

Related to service provision, the presence of a disabilityi.e., the correct disability label-is a necessary prerequisite to receive services in special education or many communitybased agencies. We have found that securing a common disability label between education and social service agencies is confusing, difficult, and too often precludes or delays provision of services. And, because of the very nature of the antisocial syndrome, many agencies will have to be involved in service provision to address the varied needs of the individuals who will be served in vocational and transition programs. Stated otherwise, adolescents who present extreme forms of antisocial behaviors present related behaviors (e.g., criminality, school failure, substance abuse, aberrant sexual behaviors) that will require specialized staff and programs to address effectively - a fact that mandates the involvement of multiple agencies in service provision efforts.

Related to interpreting research findings, most of the available research on transition outcomes has been conducted on individuals who have been served under the purview of special education, meaning that they are individuals who have received a special education label. As we discussed above, these samples almost certainly do not represent all adolescents and young adults with EBD and, thus, present a skewed view of transition adjustment for this broader population. This caveat should be considered when reading the following section.

\section{Transition Outcomes}

As we mentioned previously, hundreds of studies have been conducted on the transition adjustment of persons with disabilities, including those with ED. A comprehensive discussion of all of these studies is far beyond the scope and purpose of this article. Accordingly, and in line with current transition regulations, we address four transition outcome areas: employment, education, social experiences, and affiliation with community-based agencies. To profile these areas, we rely on data from the National Longitudinal Transition Study (NLTS), with a nationally representative sample of participants with ED, and from other selected studies.

The specific findings from these studies show variability. Space precludes both presentation and discussion of these differences, which probably is a result of variations in labeling, data collection procedures, and characteristics of the individuals who volunteer to participate in the studies and who can be contacted to provide data. In the following paragraphs, then, we provide a general overview of these findings, painting a context for vocational and transition service provision.

\section{Employment}

Meaningful and well paid work is one of the hallmark outcomes for adults in the United States. At least a portion of all adolescents who leave school will secure positions that foretell the potential for family-wage careers, whereas a sizeable portion will engage in entry-level work as a "stopping point" while in training for a career or on the way to advanced placements (Crites, 1989). Given this, the employment data for persons with ED is disheartening.

In the NLTS sample of participants with ED (D'Amico \& Blackorby, 1992), less than 2 years after leaving school, $59.3 \%$ were unemployed, and 3 to 5 years after leaving school, $52.6 \%$ were unemployed. A total of $19 \%$ had lost a job between these two times, and $23.7 \%$ had been employed at both data collection points. Of those who were employed 3 to 5 years after high school, $12.4 \%$ were working parttime, $35 \%$ were working full-time, and their median hourly wage was $\$ 3.35$.

By way of comparison, for all participants in the NLTS and less than 2 years after leaving school, $54.3 \%$ were unemployed, and 3 to 5 years after leaving school, $43.2 \%$ were unemployed. A total of $13.3 \%$ had lost a job between these two times, and $33.4 \%$ had been employed at both data collection points. Of those who were employed 3 to 5 years after high school, $12.4 \%$ were working part-time, $35 \%$ were working full-time, and their median hourly wage was $\$ 4.00$.

Also, NLTS participants with learning disabilities, less than 2 years after leaving school, exhibited an unemployment rate of $40.8 \%$, and 3 to 5 years after leaving school, $29.2 \%$ were unemployed. A total of $12.4 \%$ had lost a job between these two times, and $47.2 \%$ had been employed at both data collection points. Of those who were employed 3 to 5 years after high school, $14.1 \%$ worked part-time, $56.7 \%$ worked full-time, and their median hourly wage was $\$ 4.05$. 
Finally, for adolescents without disabilities and 3 to 5 years out of school, overall employment was $69 \%$ and part-time employment was $46 \%$.

In contrast to these other standards, participants with ED in the NLTS exhibited high unemployment, less stability in terms of keeping a job, worked fewer hours, and earned lower wages. Projects conducted in Washington (Edgar \& Levine, 1987; Neel, Meadow, Levine, \& Edgar, 1988) and Oregon (Benz \& Halpern, 1993) provide results that reflect this generally poor profile for adolescents with ED. Studies from Iowa (Carson, Sitlington, \& Frank, 1995; Sitlington, Frank, \& Carson, 1993) found slightly higher-but still low-employment rates, hourly wages, and hours worked per week among their respondents with ED.

\section{Education}

There is considerable speculation that successful instruction offered in high school, coupled with school completion, will positively influence vocational achievement as well as enrollment in postsecondary education programs for students without disabilities (Steinberg, Greenberger, Garduque, Ruggerio, \& Vaux, 1982; Stern \& Eichorn, 1989) and students with disabilities (Edgar, 1987, 1988). In line with these assumptions, in this section we consider educational outcomes from three perspectives: (a) instructional interventions offered in the public schools, (b) school dropout, and (c) enrollment in postsecondary education.

Data from the NLTS indicated that $57.8 \%$ of the participants with ED were enrolled in some type of vocational education while in school, compared to $64.8 \%$ for all participants in the study and $64.3 \%$ for participants with learning disabilities (Valdes et al., 1990; Wagner, 1991). Through correlational procedures, Wagner (1991) found strong and positive associations with postschool employment and postsecondary enrollment, which highlight the importance of the low enrollment rates for participants with ED. Of course, simple enrollment figures do not speak to the details of this instruction. For example, data from a study in Oregon documents that more than $75 \%$ of the work placements afforded adolescents certified with a primary or secondary disability of ED through school programs ended unsuccessfully (Halpern, Doren, \& Benz, 1993).

As we noted in the previous section, research suggests that students who complete school will achieve at a higher level in employment endeavors than those who do not complete school. Consequently, dropping out of school generally is regarded as a national issue of great importance for students and for society. Various estimates suggest that roughly $20 \%$ of all adolescents without disabilities will drop out of school (Blackorby, Edgar, \& Kortering, 1991). In contrast to this standard, in the NLTS, $58.6 \%$ of the participants with ED dropped out of school, as compared to $37.1 \%$ for all participants and $35.6 \%$ for participants with learning disabilities - far and away the highest dropout rate of any disability group. These findings are critical, as dropout status was associated with poor employment and community adjustment experiences in the NLTS (Wagner, Blackorby, Cameto, \& Newman, 1993 ), a finding that has been replicated in other state-level studies (e.g., Carson et al., 1995).

In the NLTS and fewer than 2 years after leaving high school, $17 \%$ of participants with ED enrolled in postsecondary programs, whereas 3 to 5 years after leaving, $25.6 \%$ of the sample had enrolled. Fewer than 2 years after leaving high school, $14 \%$ of all participants and $13.9 \%$ of participants with learning disabilities had enrolled in school, whereas 3 to 5 years after high school, $26.7 \%$ of all participants and $30.5 \%$ of participants with learning disabilities had enrolled in community college or short-term training programs (Marder, 1992a). As further comparison, during this same time period, $53.1 \%$ of all youth in the general population enrolled in postsecondary education less than 2 years after leaving high school and $68.3 \%$ enrolled 3 to 5 years after high school. These disappointing postsecondary enrollment rates also have been replicated in other state-level studies (e.g., Edgar \& Levine, 1987; Malmgren, Neel, \& Edgar, 1998; Neel et al., 1988).

\section{Social Experiences}

In this section we address post high school living arrangements and, in line with the conceptualization of the antisocial syndrome (Donovan \& Jessor, 1985), we consider antisocial behaviors from the perspectives of parenthood, criminality, and substance abuse. We also discuss the victimization of adolescents with ED in transition, as there is a logical connection between committing antisocial acts and being treated in a similar manner (Doren, Bullis, \& Benz, 1996b; Singer, 1987).

After leaving school, the great majority of adolescents with disabilities, including those with ED, continue to live with family or in some type of supported living arrangement (Newman, 1992). After being out of school 3 to 5 years, however, these situations change as adolescents begin to seek independence. In the NLTS, 3 to 5 years after leaving school, $40.2 \%$ of participants with ED were living independently, compared to $37.4 \%$ of all participants and $44.1 \%$ of participants with learning disabilities. Also, in the NLTS and 3 to 5 years after leaving school, a number of adolescents with disabilities will be faced with parenthood; specifically, $25.6 \%$ of participants with ED and $26.9 \%$ of participants with learning disabilities were parents.

Approximately $20 \%$ of all adolescents by age 17 commit an offense that, if caught, would be of a magnitude for which he or she would be arrested; and $17 \%$ of all arrests in the United States in 1986 were of persons under 18 years of 
age (Dryfoos, 1990). Wagner and Shaver (1989) noted that in the NLTS, almost $50 \%$ of the participants with ED had been arrested while in high school. Wagner (1991) noted that $58 \%$ of the sample participants were arrested at least once 3 to 5 years after leaving school, $73 \%$ of the participants with ED who dropped out had been arrested at least once, and there was a $20.7 \%$ increase between less than 2 years and 3 to 5 years after leaving school-the highest of all disability groups.

In a study in Oregon and Nevada (Doren, Bullis, \& Benz, 1996b), participants with ED were 13.30 times more likely to be arrested while in school, compared to peers with other disabilities. In looking at arrest status 1 year after leaving school, individuals who had been previously arrested in school were 4.72 times more likely to be arrested again than participants who had not been arrested previously, and individuals with ED were 16.88 times more likely to be arrested as compared to all other participants in this time frame.

Probably because of disclosure and confidentiality issues, data on drug abuse among adolescents with disabilities are somewhat scarce. The National Institute of Drug Abuse (1988) estimates for the 15- to 17-year-old group, who were considered as "heavy users," as follows: alcohol-12\%, marijuana- $4 \%$, and cocaine- $-3 \%$. In a study in Oregon, Doren (1992) found that participants with ED admitted to using alcohol in excess of these heavy user percentages and used other illicit drugs on par with these rates. Also, in one of the vocational and transition projects we have conducted (Bullis, Fredericks, Lehman, Paris, Corbitt, \& Johnson, 1994), we found that more than $70 \%$ of the participants had been treated for substance abuse upon entry into the program. Further, a history of substance abuse and substance use while receiving services were strongly related to success in job placement (Bullis, et al., 1994).

In a study in Oregon and Nevada, Doren et al. (1996) conducted one of the few investigations to look at victimization experiences (i.e., whether the respondents had been teased or bothered, had something stolen from them, or been hit hard or beaten up). They found that an individual who was ED and who scored in the lower half on a measure of personal/social achievement was over 20 times more likely than peers without these characteristics to have experienced victimization.

\section{Affiliation with Community-based Agencies}

Given the multifaceted nature of ED, as well as the dismal transition achievements of students with ED, one would think that they would receive services from a number of community-based social service agencies. The NLTS (Marder, Wechsler, \& Valdes, 1993), however, found that only $5.7 \%$ of participants with ED received services from vocational rehabilitation, compared to $12.7 \%$ of all participants and $9.6 \%$ of participants with learning disabilities.
These findings were corroborated in a study in Washington state (Kortering \& Edgar, 1988), in which only 5\% of the respondents with ED were served by vocational rehabilitation. Last, in the NLTS and according to parent reports regarding their son or daughter with $\mathrm{ED}, 43.9 \%$ of participants with ED had a need for personal counseling but only $27.1 \%$ received services (Marder et al., 1993).

\section{Recap}

Taken together, the data presented above certainly underscore that the transition experiences of these students are bleak and that they do enter a "cold world." Individuals with ED usually will not receive vocational education training while in school, most will exit school unsuccessfully, and few will enroll in postsecondary education programs upon entering the community. After leaving school, members of this group tend to enter the workforce, exhibiting a pattern of changing jobs and overall high unemployment; if employed, they tend to secure entry-level positions and work fewer hours and earn less money then peers who have other disabilities. Many will continue to engage in antisocial behaviors (e.g., criminality, substance abuse, sexual behavior) that were evident during their school years, and the majority are arrested at least once upon leaving school. Finally, despite their apparent needs, only a small segment secure support services from community-based social service agencies.

Clearly, this is a difficult population with which to work, and it poses distinct service-delivery challenges. The question that then must be asked is, "How should vocational and transition services be structured to be as effective as possible and address the unique and very real needs and challenges of adolescents and young adults with EBD?" In the rest of this article, we present what we believe are logical service-delivery answers to this issue.

\section{MODEL DEMONSTRATION PROGRAM DESCRIPTIONS}

We base many of the following recommendations for the design of vocational and transition programs and related service activities for adolescents and young adults with EBD upon two model demonstration projects that we have conducted in various parts of the country. We first describe these two projects briefly and end the section by identifying key components of those programs, services that we believe should comprise the basis of vocational and transition programs for this population in other locations and settings.

\section{Job Designs}

Over the past decade Bullis and his colleagues have operated Job Designs, a model demonstration, vocational, 
and transition project for adolescents and young adults with EBD in western Oregon, through a continuing line of federal funding (Bullis, 1992, 1995b; Bullis et al., 1994; Bullis \& Paris, 1995; Fredericks \& Bullis, 1989) coupled with state and local contracts from vocational rehabilitation, mental health, and juvenile corrections.

Job Designs is located in a decidedly rural setting just outside a town of approximately 45,000, in which a major university is located. Unemployment in this locale is low (unemployment in this county typically runs on the order of $3 \%$ to $4 \%$, well below both state and national standards) and the major employers in the locale are the university, the local school system, a large computer manufacturer, software and computer support companies, and various agricultural, construction, and timber businesses.

Since its inception in 1989 , the project has been located on the campus of a residential mental health treatment facility for children and adolescents (ages 12 to 18), who had been removed from their natural homes by order of the juvenile or children's welfare authorities. The facility maintains a census of around 80, with a 4:1 male-to-female ratio of residents and an average length of stay of approximately 11 months. At the time Job Designs began, there was no coordinated vocational program that emphasized competitive employment interventions for the residential population or for other adolescents and young adults with EBD in the general area. Thus, the focus of the project has been on providing transition services for facility residents to move into the community or to provide similar types of services to individuals with EBD residing in the community.

The project has been staffed with a part-time coordinator, who oversees daily operations of the project and who assumes responsibility for general administrative activities, and two or three transition specialists. The transition specialists are responsible for service delivery to participants in the project, services that emphasize vocational placement and service coordination among community-based social service agencies. They also complete data-collection instruments to describe the participants, the services they receive, their experiences while in the project, and their adjustment experiences after leaving the project.

Although a number of individuals have been employed as transition specialists, generally these positions are filled by individuals with some college or a bachelor's degree and with extensive experience in work programs for persons with other disabilities (e.g., developmental disabilities). Transition specialists typically maintained a caseload of 10 to 15 participants, with 5 or 6 actively seeking work or requiring intensive staff support and supervision. In addition, support groups and social skill training classes were offered as a continuing part of the program, to provide socialization opportunities for the participants, as well as structured learn- ing opportunities to foster their transition into adult roles in the workplace and the community.

Over this period 1992-1995, 79 persons were formally accepted into Job Designs, with 17 being the modal age of entry into the project. Of the total, 34 (43\%) were eligible to receive special education services for an emotional disorder, which usually coexisted with a learning disability, and the rest either had been formally certified at some earlier point or were diagnosed with some type of psychiatric label (e.g., conduct-disordered, unipolar or bipolar depression).

Further, $31(39 \%)$ had received treatment for substance abuse; $25(32 \%)$ had at least one documented instance of attempted suicide; 40 (51\%) had been adjudicated-usually for a misdemeanor or felony related to a property crime (e.g., theft, unauthorized use of a motor vehicle), but 51 admitted to having continuing contact with legal authorities regarding criminal acts; 24 reported living most of their lives in a single parent home, and $18(23 \%)$ had lived most of their lives in an institutional or a foster home arrangement; $32(41 \%)$ had at least one immediate family member who had been convicted of a crime; and 33 (42\%) had at least one documented instance of having run away from a previous living arrangement.

While in the project and receiving services, 56 of the participants $(71 \%$ of the total number of persons accepted into the project) were placed in one or more competitive jobs, for a total of 79 different placements. Only 18 of these placements $(23 \%)$ ended by the participant being fired. A total of $29(37 \%)$ of the placements ended by the participant quitting, and 21 of those were judged by project staff to have been done correctly (e.g., giving notice, telling the employer why he or she would be leaving the position). On average, those who worked were paid between $\$ .25$ and $\$ .50$ above minimum wage and worked roughly 20 hours/week.

Of the 53 participants who left the program (usually because of moving out of the area), 11 (21\% of those who left the project) dropped out of school, 16 (30\%) completed high school, and 26 (49\%) maintained enrollment in some type of educational program while in Job Designs. The typical participant also was connected with and received services from three or four different educational or social service agencies. Finally, 36 participants were interviewed at exit regarding their impressions of the project. Of these, 24 stated that they would recommend the project to their peers, and on a 4 -point Likert scale ( $1=$ low to $4=$ high), on average they believed the staff members were helpful to them $(\mathrm{M}=3.31)$ and that they gained important skills during their affiliation with Job Designs $(\mathrm{M}=3.00)$.

\section{Project RENEW}

Cheney and his colleagues (Cheney, Hagner, Malloy, Cormier, \& Bernstein, 1998; Cheney, Malloy, \& Hagner, 
1998; Malloy, Cheney, \& Cormier, 1998) began Project RENEW (Rehabilitation, Empowerment, Natural Supports, Education and Work) in 1995 with a 3-year grant from the Rehabilitation Services Administration. The grant was designed to improve transition outcomes for adolescents or young adults with ED or psychiatric conditions. Since the end of federal funding in 1998, RENEW has become a nonprofit agency in the city and continues to provide services through contracts from mental health and other social service agencies.

RENEW was developed and implemented in Manchester, New Hampshire, a city of approximately 100,000. At the inception of the project, adolescents and young adults with disabilities had the highest unemployment rate (more than $40 \%$ ) and dropout rates (more than 50\%) in the state, as well as the lowest involvement in postsecondary education and job training (Lichtenstein \& Nisbet, 1992). In light of these dire statistics, a planning committee representing the school district, mental health agency, vocational rehabilitation, community technical college, children and youth services, family support, and the city's economic development council cooperated in the project development. Once the project was funded, middle managers from these agencies and groups formed an interagency council to pursue improved educational, employment, and independent living outcomes for adolescents and young adults with EBD.

The interagency council decided to locate the project at the Manchester campus of the New Hampshire Community and Technical College, a setting that was viewed as valued and normative for this population and age range. The council also perceived it as a setting that would reinforce the importance of education and the goals of completing high school and enrolling in postsecondary education.

The project staff included a full-time director, two career and education specialists (CES), a graduate assistant from the local college, and a clerical assistant. Each project participant was assigned to one of the CESs, who served as their service coordinator. The CES worked closely with project participants to bridge the gap between young adults and community agencies. This service coordination supported young adults in pursuing specific goals of high school completion, employment, participation in postsecondary education, and community adjustment. Participants in RENEW were recruited from the Manchester School District, the local Division of Vocational Rehabilitation office, and the Manchester Mental Health Clinic. Special education coordinators and teachers, mental health clinic counselors, vocational rehabilitation counselors, and family support groups, were all given flyers regarding RENEW and were asked to refer students in need of service coordination.

Though the project emphasized vocational placements, service coordination, and social support and skills training, two features of the project were unique and emblematic of service provision. First, mentors were matched to participants based on common vocational or recreational interests. Mentors typically were co-workers in the participant's workplace who assisted in achieving employment success, or academic tutors who helped the individual achieve education goals. Each mentor developed a written statement of the goals of the mentoring relationship with the participant and coordinated mentoring activities with the CESs. A number of the mentors were paid a nominal fee for their services, but many others volunteered their time. Second, a flexible fund of $\$ 15,000$ was established to provide quick access to resources to meet urgent needs (e.g., emergency housing or transportation, tuition, supplies, clothes, or equipment). Participants applied for the funds through a one-page request form, which was evaluated by project staff. Funds then were accessed within 24 hours after approval.

Participants having a special education label of emotional disturbance or diagnosis of mental illness between the ages of 16 and 22 were accepted into RENEW. In year 1 of the program, 18 young adults agreed to participate and were enrolled. In year 2 the population grew to 25 , and by the end of year 3, 32 participants had entered RENEW.

Demographic and outcome data were kept on the year 1 participants over a 2-year period. As a group, the mean age of these 18 young adults ( 12 males and 6 females) was 18 years, 11 months. All were Caucasian. They were an older group of people who had left high school and were referred by the schools and mental health agency because of concerns regarding their community adjustment, particularly in areas of completing or furthering their education, employment, or stable community living.

When they entered the program, 7 (39\%) had completed high school and only $2(11 \%)$ were working. Thirteen of the young adults had histories of assaults, aggression with school personnel, peers, and family members; drug and alcohol abuse; and sexual offenses. The other five had issues with internalizing behavior patterns and were prone to passivity and depression. In addition, 10 had psychiatric diagnoses that included bipolar disorder, major depression, borderline personality disorder, post-traumatic stress disorder and schizophrenia (Hagner, Cheney, \& Malloy, in press). Overall, the group was viewed as in great need of assistance in the transition to adulthood to improve outcomes in education and employment.

During the 2 years of RENEW, these young adults showed consistent and positive gains in transition outcomes relating to education, work, and community adjustment. Within this period, 17 (95\%) of the participants graduated or earned some form of high school completion document (General Equivalency Diploma or the Adult Basic Education Diploma). Of those who did graduate, $9(50 \%)$ entered into some form of postsecondary education. 
Employment histories also improved, with this cohort's average wage becoming $\$ 6.19$ per hour, working an average of 28 hours per week, and the duration of work averaging 14 weeks. Jobs worked included fabricating, telemarketing, auto technician, plumber's assistant, cashier, laundromat assistant, and stock clerk. Flexible fund use has averaged $\$ 1,111$ per individual and has been used primarily for education, transportation, emergency food, and housing expenses.

Self-assessments completed at entry and at 2-year followup indicated that the participants were much more satisfied with their work, schooling, progress toward life goals, and handling of life problems after 2 years in RENEW (Hagner, Cheney, \& Mallow, in press). The greatest difficulty for the group was the issue of stable housing. Throughout the project, participants had difficulties maintaining apartments, living with families of origin, or living with friends or partners (Malloy, Cheney, \& Cormier, 1998). This problem underscores the importance of considering this group's entire community adjustment profile when providing transition services.

\section{Key Service-Delivery Components}

Both Job Designs and RENEW were developed to address the unique, multiple service needs of adolescents and young adults with EBD. Our common goals were to (a) offer and orchestrate these services to address the complex, immediate needs the participants presented, and (b) expand the participants' personal and economic capacities to foster maximum independence in solving problems associated with living and working as young adults in our society. Several service delivery components common across these two projects are critically important to include in other, similar projects for this specific population, which we discuss individually in the following sections. Before doing so, four structural and philosophical elements of the projects are highlighted, as we believe these characteristics were crucial for this program and participants and provide elements that should be embodied in other similar programs and locations.

First, though both projects served individuals who were school age, neither was located on high school campuses or affiliated solely with the public schools. The vast majority of the people with whom we worked had not been successful while in school. They were highly "school-phobic" and had an aversion to being at and around schools.

Anecdotally, we were surprised that many of those we worked with - who had lengthy histories of antisocial behavior-were actually fearful of returning to the school setting. Moreover, even the participants who attended school did so sporadically and were not truly invested in their classwork. Accordingly, that the projects were not located on a high school campus or focused primarily on academic achievement. Job Designs was located away from a school setting, and RENEW at a community college that the participants viewed to be a safe place to come for meetings.

The projects' administrative structures and locations also allowed us the flexibility to serve participants in community settings, where the individuals we worked with as well as many of the services they needed were located. We doubt that had our staff been tied to a high school building and its schedule, we would have been able to offer the same level, intensity, and quality of services to these decidedly "out-ofschool" individuals. The locations did have drawbacks, as we often wished for a closer connection with high school programs and services than was possible.

Second both projects maintained relatively low staff-toparticipant ratios-generally 1 to 12 to 15 , but in reality lower, as only a portion of these participants were "active" at any given time. Though these ratios may be viewed as impractical given the fiscal constraints facing schools and social programs, we strongly contend that by maintaining these low ratios, the staff could develop close, and meaningful relationships with the participants and their families. Also, by maintaining a low staff-to-participant ratio, progress and needs of those with whom we worked could be carefully and closely monitored.

The time intensity of these services must be realized. This population poses incredibly demanding and all too real service delivery challenges that seem at times to consume every working and waking hour. Higher staff-to-participant ratios simply would not have afforded the same amount of time to provide these services or to develop the relationships necessary to shape meaningful service-delivery efforts and would have been economically disadvantageous, as these arrangements would not have been as effective as the services we were able to offer.

Third, the importance of the transition specialist, or career education specialist, in these types of projects cannot be underestimated. The relationships these staff members maintained with the participants were crucial to the structure and success of both projects. These relationships provided the foundation to maintain the participants' interest and motivation to be involved in the projects and by which to forge interventions that were focused on the individual and his or her unique needs and goals. Bullis and Clark (in press) provide details on the roles and responsibilities of these staff members. Clark (1998) identified the following six fundamental guidelines for this position's role and work responsibilities.

1. The staff must be consumer-centered.

2. Services must be individualized and encompass all transition domains.

3. Services should focus on each individual's special characteristics, strengths, interests, and needs. 
4. The staff must provide an unconditional safety net of support to the project participants.

5. Transition services must be provided in a manner that ensures continuity of effort and support from the participants' perspective.

6. Services should have an outcome orientation.

Fourth, both projects practiced a zero-reject and unconditional care model, providing services to persons in need and supporting them through intensive interventions even when they were presenting conditions that could be dangerous to themselves or others. Despite knowing in advance that we would work with a difficult clientele and having an awareness of the challenges this population would pose and their need for intense services, we constantly confronted significant problems from the participants. Most of the individuals we worked with presented long histories of personal, social, and educational difficulties, the effects of which were deeply ingrained in their being. Although we had, and have, great respect and admiration for staff members' work and the participants' successes, in many cases the services we were able to provide simply were of too brief duration or intensity to address the needs of these individuals adequately. We have come to agree strongly with Kazdin's (1987a, 1987b) and Wolf et al's (1987) recommendations that services for many persons with EBD must be considered from a long-term, and in some cases, lifelong perspective.

In reality, this means that participants will be given many more chances than is typical in a usual vocational and transition program for persons with other disabilities, that longterm supports and services should be developed to support these individuals over time, and that our concept of transition "success" must be reconsidered in terms of these individuals' significant challenges and needs. Although adolescents and young adults with ED may be considered as having mild disabilities from a special education perspective, many persons with EBD will not carry a formal disability designation, implying that they are less challenged than those who are formally labeled. The simple fact is that long-lasting success is difficult to achieve with people who have these types of emotional or behavioral characteristics through any short-term intervention.

Having said that, we also believe that vocational and transition programs for this population can be more successful than they are and can be structured to address both the immediate and the longer-term needs of these people. To be effective for this population, transition programs should have key elements of general transition programs for adolescents and young adults with other disabilities (Kohler, 1993), structured social support programs (Dryfoos, 1990; Kazdin, 1987a, 1987b), and psychiatric rehabilitation services (Anthony, 1979). Specifically, vocational and transition programs for adolescents and young adults with EBD should include the following components (Bulls \& Fredericks, in press):

- Intake and functional skill assessment

- Personal futures planning

- Community-based wraparound social services

- Competitive employment

- Flexible educational experiences

- Social skill training

- Long-term support and follow-up services

\section{Intake and Transition Skill Assessment}

In our experiences, many of the individuals referred to our projects have (a) minimal work experiences, (b) ill defined goals and aspirations at the beginning of services, and (c) less than developed work, education, and community living skills. Also, referrals tend to cluster into two groups: (a) those with extensive assessments and numerous reports, and (b) those for whom little formal assessment and background information is available. Sometimes for the latter group, agencies or referring agents are reluctant to be entirely forthcoming regarding certain individual's backgrounds, probably because of concern that the individual would not be accepted into the program if the complete history were known. If a person has had numerous assessments, organizing and integrating the results into a coherent package is difficult. Or the assessments may focus on abstract cognitive or psychological traits with only a tangential relationship to transition-related skills and activities for this population. If a person has scant assessment data, we have to begin from scratch to gather appropriate psychological, social, and educational information. For most of the persons with whom we have worked-even those with extensive assessment histories-we have had to conduct assessments to ensure the establishment of an accurate profile of the individual's strengths, problems, and interests.

The importance of gaining a clear and accurate picture of an individual before beginning work with him or her cannot be overstated. If a referral's tendencies to perform certain antisocial acts, such as arson or stealing, are not known, that person may pose a distinct threat and danger to others in a community work or living placement. Even though intake should be conducted as quickly as possible to avoid "losing" the referral while waiting for services to begin, beginning service delivery before a complete history can be established would be unethical and irresponsible.

At referral, complete and current social, criminal, educational, and psychological reports should be gathered for each person. Generally, we require that the referring agency provide the bulk of these materials for a preliminary review by the project staff. Most referrals can be processed relatively quickly, with the necessary information on which to 
base service delivery being amassed in 1 or 2 weeks. In some instances, though it has taken more than a month to secure necessary reports. This process also should involve the individuals, so they can get to know the transition specialist with whom they will work and the staff person can get to know them.

At this point, meetings can consist of both informal discussions and formal, semi-structured interviews that address the individual's vocational experiences, goals, interests, strengths, and concerns; social and family information; and residential information. Questions also should be asked about his or her typical daily schedule. Some people with whom we have worked simply do not arise in the morning, which precludes--at least for some period of time-work placements that begin in the morning.

Most of the referrals to our programs have some type of work experiences. These placements, though, often have been short-term or ended unsuccessfully. Thus, a person's career interests-especially at the point of referral-may not be clear or realistic. Questions the staff asks, in that case, should focus on the person's general skills, interests, preferences, dislikes, and hobbies, so as to form initial service delivery plans and directions.

Once basic referral information has been secured, assessment efforts will tend to be directed at two basic issues: (a) eligibility for services from educational programs and social service agencies, and (b) assessment of work and transition skills. Securing eligibility for services from various agencies for persons with EBD can be confusing and difficult. Again, a portion of this population, who may not carry a formal disability designation, could be so labeled. Although we strongly believe that labels should not be applied merely as a matter of course, the reality is that access to many types of educational and social services is predicated upon having a certain label. Within education, this means a special education designation and in community-based agencies, at least for this population, it may mean having a psychiatric diagnosis (American Psychiatric Association, 1994). For a number of the participants in our projects, we had to coordinate assessment primarily for the purpose of establishing eligibility for certain services.

The relevance of traditional assessment data for applied issues such as working and living in society is controversial (McClelland, 1973). Specifically, questions arise regarding the relevance of the results of traditional intelligence (e.g., IQ) and personality (e.g., MMPI) measures to the vocational and transition skills and performance of persons with special needs (Frey, 1984; Halpern \& Fuhrer, 1984). This concern is important, as assessment data should serve as the basis for planning interventions and evaluating the impact of those interventions on the individual. The content relevance of traditional assessment tools to the pragmatic focus of vocational and transition programs, however, is unclear. For example, in reviewing the psychiatric literature on the relationship of psychometric data to work, living, and rehabilitation outcomes, Cohen and Anthony (1984) concluded that:

- Measures of psychiatric symptoms do not predict vocational rehabilitation outcome.

- The psychiatric diagnosis does not predict vocational rehabilitation outcome.

- Measures of psychiatric symptoms do not correlate with the psychiatrically disabled person's skills.

- Measures of skills do predict vocational rehabilitation outcomes.

Hursh and Kerns (1988) took a similar position regarding the relevance of traditional assessments for adolescents with EBD in vocational programs. Because the overriding characteristics of this group relates to their social behavior, assessments of these skills relative to specific settings, such as a work placement have to be conducted. In the position statement of the Council for Exceptional Children's Division on Career Development (now Division on Career Development and Transition) on career/vocational assessment, Sitlington, Clark, Brolin, and Vacanti (1985) also recommend that frequent and flexible assessments related to the specific work or transition skills in question be the preferred assessment approach with adolescents who have disabilities in vocationally oriented programs.

Complete discussion of the myriad of possible assessment instruments relative to transition services for this population is far beyond the scope of this article; therefore, we suggest that interested readers review the following selected references for more complete information on this program component. Cobb and Lakin (1985) presented an assessment model for vocational and transition programs that emphasizes skill checklists, rating scales, and interviews that can be administered quickly and at multiple times to chart the individual's growth and changes. An excellent book by Hursh and Kerns (1988) provides an overview of assessment procedures with applicability for transition programs for youth with EBD. Bullis and Davis (in press) present a model of functional assessment for use in organizing existing assessment data as well as assessments for making initial transition and rehabilitation plans.

\section{Personal Futures Planning}

According to the 1997 Amendments to the Individuals with Disabilities Education Act, transition services involve a coordinated set of activities for a student with a disability that promote movement from school to post-school activities, including postsecondary education, vocational training, integrated employment (including supported employment), 
continuing education, adult services, independent living, or community participation; and that is based on the individual student's needs, taking into account the student's preferences and interests. In addition, the federal law indicates that, when appropriate, students with disabilities should be invited to, and serve as a member of, their individualized education program (IEP) team. Along with the student, the team should include representatives from other agencies that are likely to be responsible for providing or paying for transition services. After age 14, students are to be informed that the purpose of their IEP meeting is to develop statements concerning transition services, and at age 16 , to consider needed transition services.

Furthermore, the IEP now must include positive behavioral interventions, strategies, and supports for any student whose behavior impedes his or her learning. When an older, and potentially out-of-school, referral is received, similar types of planning, with potentially different agency representatives, should be involved in the process. At the meetings, the individuals must be prepared to advocate for their own goals, objectives and services, thereby providing one way for individuals to direct their lives, accomplish their goals, and gain decision-making competence and maturity.

Everson (1993) suggested a step-wise process involving the student, family members, school, and community personnel in the development of these transition plans.

1. School personnel compile a list of students yearly who are eligible for transition services.

2. A transition team composed of educators, family members, and agency members is formed for each student. The extent of involvement of any team member varies depending on the student's transition goals.

3. A transition planning meeting is held prior to an IEP meeting so the transition plan can drive the goals and objectives of the IEP.

4. Transition coordinators are clear with members about the purpose of all meetings and written materials, and home visits are provided to prepare families and students for transition meetings.

5. The transition meetings are held on scheduled dates, and the meetings follow an organized agenda. Release of information forms are completed, areas to be planned are discussed, terms (e.g. supported employment) are clarified, and a vision for the student's successful transition is determined.

In addition to its being a legal requirement for transition services, involving the individuals in the design and implementation of their service plan makes sense and represents a level of responsibility, decision-making competence, and empowerment that is a critical transition outcome (Halpern,
1993, 1994; Szymanski, 1994). Both Job Designs and RENEW employed procedures similar to Everson's (1993) model, including and involving their participants centrally in planning their own interventions. These meetings brought the staff and participants together to discuss service delivery and changes in plans.

In this section we focus on RENEW's personal futures planning (PFP) as practiced in RENEW, which was based on the McGill Action Planning System (MAPS) (O'Brien, Forest, Hasbury, \& Snow, 1987; Vandercook, York \& Forest, 1989). MAPS has been used widely as a problem solving approach to plan transition goals for students with severe and/or developmental disabilities. These procedures were adapted to the EBD population and tended to conform to the following pattern.

A typical PFP usually preceded the formal IEP or transition meeting and included the participant, a friend or family member, and school or agency representative-or may include only the participant and staff member, depending upon the situation. The planning should help students and the staff delineate the individual's vocational interests and dreams. The specific steps of this process include: (a) writing the individual's personal history, (b) identifying family, friends, and community social supports, (c) determining the individual's dreams and fears, (d) translating dreams into goals, (e) developing quarterly actions to move toward goals, and (f) evaluating movement toward goals every quarter.

The outcome of the meeting is a personal plan that identifies an individual's personal goals, fears, and interests. The personal futures plan (PFP) is an ideal way to develop goals and objectives in the individual's IEP and general transition plan that may be used in conjunction with other agencies. For example, after completing the PFP process, individuals can bring their goals and objectives to the IEP meeting or to their meeting with the mental health or vocational rehabilitation staff, to advocate for services that meet their needs. For maximum impact, the PFP should be matched to short-term objectives with educational or vocational activities. This translation of the PFP to an action plan provides direction and guidance for the immediate services and for considering alternatives to achieve longer term life goals. The PFP also should be monitored constantly by the participant and staff person, and updated when objectives are met or circumstances change.

In Malloy, Cheney, Hagner, Cormier, \& Bernstein (1998), two adolescents were described who used their PFP within the context of IEP and transition meetings. The first young woman's PFP suggested the need for major changes in her IEP. The RENEW career and education specialist helped her to develop a presentation to the school district representatives. The participant presented to the IEP team, and each member agreed on the individual's stated goals and action steps to achieve those goals. As a result of this meeting, mental health clinical services were adjusted to fit her goals, and 
the school district agreed to pay for a class at the local community college and for an internship at a local business site.

Another RENEW participant was cutting high school classes regularly and getting into legal trouble for shoplifting at the local mall. In reviewing her PFP, she stated that schoolwork was boring, the class size was overwhelming, and her friends encouraged her to cut classes. She requested an alternative education program would benefit her ability to learn and attend classes, and her challenge was to convince the school representatives to support this alternative. She requested an IEP review meeting, planned for it by putting her ideas on note cards, and used her notes to prepare her plan and answer questions during the meeting. Her preparation and self-advocacy skill led to new services in her IEP and transition plan.

\section{Community-based Wraparound Social Services}

General service delivery to adolescents and young adults with EBD, and specifically transition-related service delivery, has been viewed as disconnected, inefficient, and associated with ineffective outcomes (Knitzer, Steinberg, \& Fleisch, 1990). Adolescents and young adults with EBD disrupt ties with support systems when they stop going to school and do not use nor access mental health or other social services (Knitzer, 1993). This time of life is particularly difficult for persons with EBD and the movement into adulthood can be fraught with difficulties.

A coordinated system of care is required to help them achieve career or education goals (Louri, Stroul, \& Friedman, 1998), which should include schools, mental health providers, rehabilitation, social service agencies, and families working together (Knitzer, 1993). Contemporary special education transition practices of transition coupled with wraparound services, from a mental health perspective, provide a framework for coordinating services for adolescents and young adults with EBD (Eber, Nelson, \& Miles, 1997; Lourie, Stroul, \& Friedman, 1998; Stroul, 1993; Nelson \& Pearson, 1991). The 1997 Amendments to the Individuals with Disabilities Education Act mandates transition planning for adolescents with disabilities through input and service delivery of an interagency team, a process that also serves as an indicator of successful practice (Malloy et al., 1998).

The Child and Adolescent Service System Program model of wraparound services (Lourie et al., 1998; Stroul, 1993) involves "wrapping" services around children and adolescents with mental health needs. It has been adopted in all 50 states through policy and practice. The overarching principles of this approach are that (Burns, Hoagwood \& Maultab, 1998):

1. Services should be individualized, based on the specific needs of the individual and his or her family.
2. Services should be family-centered and involve families in all aspects of planning and treatment.

3. Services should be community-based and provided in the least restrictive environment.

4. Services should be culturally and linguistically competent, and sensitive to cultural and ethnic values.

Wraparound services differ from the traditional service delivery system as they: (a) focus on the strengths of the individual and their family; (b) are driven by the needs of the individual as opposed needs of agencies; (c) deal with all aspects of the individual's life; and (d) provide services and support for the individual in natural settings and use social networks such as family and friends. School-based systems such as the Illinois school model (Eber, 1994; 1996) have "wrapped" supportive educational and community services around students with EBD, coordinating school and community services to promote positive outcomes. The wraparound model is highly consistent with transition planning in that it requires interagency teams to be outcome-oriented and use resources in flexible and creative ways to meet the needs of individual adolescents and is a natural extension of this approach (Eber et al., 1997).

Both Job Designs and RENEW used a wraparound approach toward service management of its participants. RENEW, however, began its activities with such a model clearly in mind and went to great lengths to establish a coordinated system of services from the outset. RENEW promoted interagency coordination on two levels: (a) service and (b) management. For service, an interagency team was formed for each young adult based on objectives in the personal futures plan. The service team typically included the individual's CES, mental health case manager, and vocational rehabilitation counselor. Special education teachers and administrators were involved whenever course credits were discussed.

The management team was composed of middle-level administrators who met monthly as an Interagency Coordinating Council (ICC). This group represented the community mental health center, vocational rehabilitation, Alliance for the Mentally Ill, school district, community technical college, child welfare state agency, and other private and public agencies that served adolescents and young adults in the city. In these meetings, problems and barriers in serving RENEW participants were identified, and then ICC members examined and tried to implement solutions to these issues.

Agency managers and service team members adopted common beliefs that valued self-determination for young adults, which was somewhat foreign to some of the staff members and the traditional service model. The RENEW staff worked to foster participants' self-determination by constantly advocating for their perspective and encouraging 
brainstorming as to how existing resources could be used to support an individual's PFP. For example, many participants did not have stable housing situations, yet a provider with a Housing and Urban' Development grant for homeless young people was unable to modify its eligibility requirements to accept RENEW participants. The ICC discussed the housing problem and agency's inflexibility at length, leading to alternative solutions for many of the participants.

Once the ICC agreed with the goals of a plan of service for an individual, specific members then played key roles in accomplishing the goals. For example, the special education director was asked to approve funding for counseling services, tutoring, transportation, and alternative education programs for participants. Without clear communication and common attainment of goals for these individuals, the director might have denied some of these requests. Likewise, vocational rehabilitation counselors agreed to pay for onthe-job training and transportation to the worksite.

A third element of successful collaboration among agencies related to the use of flexible funds. The project maintained a flexible fund account that participants could access through a simple proposal and request to the project staff. Participants have used the funds to access and pay for career-related exploration and job opportunities, internships and apprenticeships, classes, tutoring, computer software, and clothes for job interviews-thereby filling in small "gaps" between services quickly and relatively easily.

\section{Competitive Employment}

Securing a competitive job for adolescents and young adults is an important part of a comprehensive transition program. There simply is no substitute for the experiences that adolescents and young adults with EBD gain through placement in real jobs in competitive work settings. Competitive work placements provide three major benefits:

1. They provide the opportunity to learn and practice work production skills.

2. They foster job-related social skills.

3. They allow individuals to have a number of different job experiences to explore their own vocational interests and to formulate long-term career preferences.

In our experiences, participants in transition programs are all too often placed in jobs merely because the position is available, not because it is of special interest to the individual. The primary way people gain the awareness necessary to make these judgements is through having various work experiences.

Of course, the problems in providing placements must be recognized, as some portion of the participants in these types of programs display behaviors that could cause danger or harm to others in an unsupervised setting. There is a delicate balance between providing an individual with EBD a desired job placement and, at the same time, monitoring and supporting that placement so as to (a) ensure the safety of others, (b) afford the individual the learning experience and dignity of working in as unstructured and natural arrangement as possible, and (c) provide appropriate and unobtrusive support and assistance to the employer or work supervisor. In the following discussion we address how job placements can be secured and how these placements should be monitored and supported.

People in the general public usually secure jobs through personal contacts or those of family members or friends (Azrin \& Besalel, 1980)—what some term the self/family/ friend network (Edgar, 1988). In many cases, the transition staff members with whom a participant will work assume this role, capitalizing on their own contacts and social network to generate and identify possible job placement opportunities. Other placement options can be generated through job development efforts, in which the staff members contact prospective employers to promote the positive benefits of hiring someone from their program and the advantages of working with the program.

Surveys and focus groups we have conducted of the employers who hire workers from our programs suggest that most employers hire participants for three main reasons: (a) they want to offer assistance to someone in need, providing a service to the community, (b) they are impressed with the staff person who made the job development contact, or (c) they have had positive experience with other such programs in the past (Bullis, Fredericks, Lehman, Paris, Corbitt, \& Johnson, 1994; Cheney et al., 1998a).

We believe that job development should be conducted from the perspective of "selling" a product - in this case, the program participant-and the services of the program itself. To minimize the time involved in these activities, and to maximize successful responses from employers, these contacts should be made in an organized and informed manner. Preliminary contacts with employers may be accomplished through personal contacts, contacts from public forums (e.g., presentations at men or women's professional meetings), or "cold" contacts-following job openings in want ads or the phone book. Our records indicate that, of 10 phone calls to employers, two or three will respond positively and be willing to talk with a staff person about the project.

If a personal interview can be secured, roughly half of these employers have hired one of our workers. Personal meetings with employers should be brief, professional, positive, and provide the employer with information about the project and services through an attractive and short brochure. If a position is being sought for a specific individual, we suggest not to disclose specific information about the person, except as that information relates to performing the job in question. 
As a rule, we prefer that participants who are to be hired go through an actual interview with the employer. The interview affords the employer the opportunity to review and approve of the individual before hiring, which shifts the responsibility for the decision from the project staff, and offers the individual the experience of interviewing for a position.

Another consideration related to matching persons to jobs, consists of the work requirements and responsibilities associated with the placement. A fair number of the participants had difficulty keeping scheduled appointments, especially at the beginning of their association with our projects. Also, some had difficulty focusing on and physically performing some tasks for any length of time. Because one of the main goals of job placement is to provide the person the opportunity to be successful, these fundamental job deficits must be addressed during the first job placements. Figure 1 presents a five-level, developmental work structure that we have used.

There is a developmental progression between phases that reflects level of work responsibility, level of reward from the job, and the way in which the participant is monitored. This structure affords (a) a way to conceptualize and match individuals to jobs, (b) a way to monitor the individual's progress, and (c) a context for the staff to discuss with the participant how the placement is going.

We encourage using natural supports within the employment setting to make the placement as real and supported as possible (Nisbet, 1992). On-the-job mentors, who may be paid or who volunteer, can be recruited at the worksite to assist the participant in learning job tasks as well as the nuances of the social mores in the setting. Anecdotal reports from both projects indicate that these arrangements were both helpful and enjoyable to the participants.

Finally, we emphasize that people in the age range willand should - change jobs several times so they will have a number of meaningful and expanding work experiences. Adolescents and young adults with EBD are likely to change jobs several times while in a transition program. Job fluctuations should not be construed as negative in all cases, as these changes afford participants the opportunity to practice and learn job quitting, job search, and interviewing skills.

\section{Flexible Educational Programming}

Adolescents and young adults with EBD often struggle with high school completion and benefit from flexibility in their academic scheduling, curriculum, and learning environments (Bullis \& Walker, 1995; Cheney et al., 1998). Flexibility, however, is not without its unique challenges and risks. For example, truancy from an alternative school setting that is less structured and allows more freedoms than a traditional high school setting can afford leniency, which can lead to suspensions or worse. Incidents regarding drugs or weapons can lead to immediate removal from public school settings, which can disrupt transition progress and stretch the capacity of interagency coordination. For example, removal to an alternative setting may involve the mental health counselor, school representative, and director of the alternative school. Identifying strategies and solutions to reintegrate adolescents into their educational program in these situations becomes imperative so the individual can complete his or her educational objective.

Traditional educational placements have been punishing for many members of this population. Moreover, a fair portion of the people with whom we work have expressed reluctance, which sometimes borders on fear, regarding returning to these types of settings. Generally, adolescents and young adults with EBD need a flexible educational strategy approach regardless of their previous educational background and placements (i.e., self-contained or mainstreamed) (Cullinan, Epstein, \& Sabornie, 1992). Community and work-based learning structured in such a way that it allows individuals to earn educational credits has been suggested as one approach to increase graduation rates of those with EBD (Benz, Yovanoff, \& Doren, 1997; Bullis et al., 1994; Frank, Sitlington, \& Carson, 1991). Structured activities such as apprenticeships, paid work experience, and continuing education following dropping out of school should all be considered and explored as viable educational options (Benz, Yovanoff, \& Doren, 1997).

The challenge is to develop creative approaches that help these individuals to complete meaningful educational programs even after severing school ties. Although there are always exceptions, we have found it effective to guide individuals with professional aspirations toward high school degrees and those with technical or vocational interests to adult basic education programs or the general equivalency exam.

In line with these realities, flexibility in course policies and methods for earning credit are essential in many participants' objectives for completion of high school or other educational objectives. In our projects we have been able to have participants earn educational credits for school completionincluding the traditional high school diploma, general equivalency diploma, and adult basic education degree-in classrooms, on jobs, and at the local community college. These arrangements and agreements, of course, requires collaboration among the project staff, instructors, tutors, and the individual themselves to determine experiences that meet the goals outlined in each person's individualized education program or personal future plan.

Although some people with EBD are able to complete courses in general high school classes, special education resource rooms, or at a district's technical high school, many 


\section{PHASE I: Learning}

1 The vocational trainer supervises and trains the worker on all tasks and duties.

2 The worker learns various job duties required by job site.

3 The worker learns and follows all rules and regulations as posted by vocational site.

4 The worker begins to identify and work on skills and behaviors exhibited at work site.

5 The trainer collects and records all data from skill and behavior programs.

6 The trainer, in conjunction with the worker, begins to explore transportation options such as city buses, bicycling, walking.

7 The worker may begin bus training if appropriate and available.

8 The worker maintains a minimum of 3 working hours per week.

9 The trainer delivers all consequences and contacts with the worker.

\section{PHASE II: Responsibility}

1 The trainer makes intermittent quality checks while remaining on job site.

2 The worker begins to maintain various job duties independently.

3 The worker begins to follow all rules and regulations of job site independently.

4 The worker begins to set own goals with trainer and watches own behaviors.

5 The trainer collects and records all data from skill and behavior programs.

6 The worker begins transporting self using public transportation, if available with trainer guidance and supervision.

7 The worker uses vocational time wisely, maintains satisfactory work rate and quality.

8 The worker maintains at least 5 working hours per week.

9 The worker begins to receive and respond to occasional feedback from employer.

10 The trainer delivers all consequences and the majority of contacts with the worker.

\section{$\checkmark$}

\section{PHASE III: Transition}

1 The trainer is not at job site, makes intermittent quality checks.

2 The worker is independent in all job duties and tasks.

3 The worker follows all rules and regulations of job site independently.

4 The worker works toward vocational goals and maintains own behaviors.

5 The worker's skill and behavior data are monitored with travel card.

6 The worker independently transports self to and from work.

7 The worker maintains work quality equal to that of regular employee.

8 The worker maintains at least 10 working hours per week.

9 The worker responds to employer in all job-related matters.

10 The employer delivers the majority of consequences.

\section{PHASE IV: Independence}

1 The trainer makes intermittent quality checks by phone.

2 The worker is independent in all job duties and tasks.

3 The worker independently follows all rules and regulations of job site.

4 The worker continues to work toward vocational goals and monitors own behaviors.

5 The worker has no formal behavior programs.

6 The worker independently transports self to and from work site.

7 The worker maintains work quality equal to that of regular employees.

8 The worker maintains at least 10 working hours per week.

9 The worker responds to employer in all job-related matters.

10 The employer delivers all consequences.

11 The worker will be eligible for placement in paid employment with trainer support.

\section{$\checkmark$ \\ PHASE V: Employable}

1 The trainer assists with administrative issues.

2 The employer trains and manages.

3 The worker reaches vocational goals.

4 The worker independently transports self to and from work.

5 The worker maintains at least 20 working hours per week for 1 year.

6 The worker is able to independently gain paid employment 
more-especially those in their late teens or early $20 \mathrm{~s}$-will find the community technical college a viable setting for earning high school credits and earning the diploma (Cheney, Rodriguez, \& Martin, in press). For example, one participant described in Cheney, Rodriguez, \& Martin (1998) was 20 years old and 4 credits short of high school graduation. After earning 2 credits in summer school provided by the school district, he did not want to return to the regular high school to get his final 2 credits. Instead, he enrolled in classes at a local community college, where he was closer in age to most of the other students, and earned credits in the college's computerized learning laboratory to receive his high school diploma.

Coupled with educational and classroom placements, internships in businesses and organizations should be targeted to teach participants the work skills related to a specific occupation. In RENEW, internships were established for 2 to 4 weeks for participants to try a new job without any commitment on the employer's part to hire the worker, or from the participant to accept the position at the end of this time.

One young man in RENEW, for example, served as a plumber's intern for 6 weeks by studying a curriculum developed between the project staff person with whom he worked and the employer. The internship evolved into a registered apprenticeship when the employer accepted the longterm commitment to employ and train the intern (Cheney, Malloy, \& Hagner, 1998).

Similarly, on-the-job training (OJT), which involves hands-on training in a specific occupational area, should be explored. In our experience, participants who were being served by vocational rehabilitation, received funding from that agency to pay employers to spend more time with participants, providing them training in specific jobs teaching specific skills.

Ideally, these types of actual work experiences should be linked to instruction offered in classroom settings. For example, if an individual is placed in a fabric shop and required to read, add, and subtract fractions but has difficulty in basic math, it would be beneficial both to success on the job and to learning these math skills if classroom instruction were to focus on the work requirements. That is, if the academic demands of the position could be analyzed and brought to the instructional setting, the individual could be taught the skills needed for the job. This sort of instruction would be meaningful, and the job experiences would allow for applied practice.

These types of logical connections have been difficult to effect in our programs, as the connections with the world of work and the schools is only emerging (William T. Grant Foundation, 1988). Further work is needed to explore ways to establish and conduct these types of linkages between the job and educational settings.

\section{Social Skill Training}

Perhaps the most defining characteristic of adolescents and young adults with EBD relates to deficits in social skills. Competence in social interactions is crucial to peer acceptance and general life adjustment (D'Zurilla, 1986; Kelly, 1982; McFall, 1982; Parker \& Asher, 1987; Spivack, Platt, J., \& Shure, 1976; Trower, Bryant, \& Argyle, 1978), as well as transition success for persons with disabilities (Chadsey-Rusch, 1986, 1990) and specifically those with EBD (Bullis, Bull, P. Johnson, \& B. Johnson, 1993; 1994). In fact, social skill is hypothesized to be the predominant reason behind successful work placements (Chadsey-Rusch, 1986, 1990).

For example, in the original evaluation of the Job Designs project, we (Bullis et al., 1994) found that workers' problems interacting with co-workers and supervisors were strongly predictive of lack of job success. Further, through placements in competitive work, living, and educational settings, adolescents and young adults in these programs are highly likely to be faced with interacting with unfamiliar persons in unfamiliar settings and under unfamiliar rules and expectations.

Because social behavior is a major issue for adolescents and young adults with EBD, and because vocational and transition programs should prepare and support these persons for successful entry into society, emphasis should be placed on teaching transition-related social skills. The issue becomes how this type of instruction should be offered. We believe that the training can, and should, be offered through any or all of three instructional options: support groups, individual instruction, and structured classes.

Support groups are an important part of vocational and transition programs (Benz \& Lindstrom, 1997), and especially for individuals with EBD (Nishioka, in press). These types of groups usually are scheduled to meet at regular times (e.g., weekly) for 1 to 2 hours. Although staff members will be present at these meetings to provide support and monitoring, as well as to provide food and beverages, the meeting typically has no set structure, and staff members remain in the background.

Typically, and especially at the beginning of the series of meetings, the staff will set the rules for the group (e.g., no fighting, no interrupting, provide support to all there) and offer suggestions for subjects to talk about (e.g., how to interview for a job, how to quit a job, how to handle difficult coworkers). Once started, however, these sessions should be envisioned as being the participants' time, in which they can talk about issues related to their jobs, school, services, and lives. Peer teaching is a key part of social skills training, particularly when some participants have different skill levels (e.g., people with more experience and skill offer 
suggestions to persons with less experience and skill) (Kelly, 1982). There is a certain power of instruction when a specific point regarding behavior comes from a peer instead of an older staff person.

In operating groups of this type, we have been impressed with the power of the group as a support mechanism. The meetings have an ineffable quality in which participants connect with one another and offer each other support in ways and from a perspective that we cannot duplicate.

Numerous opportunities for individual instruction are offered through incidents that occur in providing services and in placement settings. These interactions take place between the transition staff and the participant either in the "moment" in the specific setting or in an interaction some time after the incident in question. Both instances offer the opportunity to teach appropriate social behavior, but the time constraints may be different (e.g., if the interaction occurs in a work setting during the job, it may not be possible to spend several minutes interacting with the participant).

In either case, we believe this type of instruction should be provided from a social problem-solving approach, as adolescents and young adults with EBD tend to misinterpret social interactions, imputing more hostile connotations to interactions than really exist and generate fewer potential solutions to social interaction issues than peers without EBD (Dodge, Price, Bachorowski, \& Newman, 1990; Dodge \& Murphy, 1984; Platt, Scura, \& Hannon, 1973; Platt, Spivack, Altman, Altman, \& Peizer, 1974; Spivack et al., 1976; Steinberg \& Dodge, 1983).

The social problem-solving approach essentially consists of several, interrelated stages (D'Zurilla \& Goldfried, 1971).

1. The individual must be taught to recognize the problem, by being guided through and being asked to describe the context in which the interaction occurred, the requirements of the setting (e.g., work settings have different rules than social settings), nuances surrounding that exchange, and the nonverbal cues from the other person in the interaction.

2. Once the situation has been defined, by identifying the demands of the setting and positions of the other persons in the interaction the individual has to generate alternative solutions or behavioral responses to the situation.

3. From this array of alternatives, the individual then decides which option would best resolve the situation.

4. The individual mentally rehearses how to perform the response.

5. Following this cognitive process, the observable behavioral response will consist of the way in which the individual expresses the content of the interaction (e.g., smiles, gestures, body movements) and the substantive content of the response.
This general approach can be applied to any number of incidents and interactions. Depending upon the participant's experience and characteristics, the staff person may have to be active in structuring these individual teaching opportunities or to take a more passive role, guiding the individuals through this process.

Of course, individual teaching is not as efficient as a group session in which a small number ( $n=8$ to 15 ) of participants are taught at one time. To our knowledge, however, only a few carefully developed and evaluated curricular packages are available for use with this population (cf., Goldstein, Glick, Irwin, Pask-McCartney, \& Rubama, 1989; Goldstein, Harootunian, \& Conoley, 1993; Goldstein, Sprafkin, Gershaw, \& Klein, 1980; Hazel, Schumaker, Sherman, \& Sheldon-Wildgen, 1981, 1982).

If a published curriculum cannot be secured, a structured class can be developed by following the social problemsolving approach described above and applying that model to actual transition-related incidents the class members encounter. For example, the group may be convened and asked to discuss the problem or concerns they encountered in the past week. From this discussion, they may be able to identify a common theme or a critical problem.

Following identification of the problem, the situation should be analyzed according to the social problem-solving approach. Class members also would be required to role-play and critique different possible interactions. More detail on this process can be found in books by Kelly (1982) and D'Zurilla (1986). A chapter by Nishioka offers a suggestion for group social skill training specifically for adolescents and young adults with EBD in vocational and transition programs.

\section{Long-Term Support and Follow-up Services}

The behaviors and problems associated with EBD are extremely durable and resistant to even the most intense interventions (Kazdin, 1987a, 1987b; Wolf et al., 1987). Follow-up monitoring of participants after they leave the vocational and transition program is a vital service component (Benz \& Lindstrom, 1997). Unfortunately, many programs with which we are familiar make little, if any, attempt to stay in contact with participants after they leave a project. Given the demands of working with people with EBD, there is no shortage of work and, not too surprisingly, participants who leave programs tend not to receive priority as they are not receiving services. Also, conducting long-term followup is time-consuming, resource-demanding, and difficult. Still, there are both service delivery and evaluation reasons for engaging in such work.

From a service-delivery perspective, former participants likely will encounter difficulties after leaving a program and may require additional support to some extent (e.g., receiving information on finding a new job to assistance in accessing 
treatment services), at different times. If contact is not made with these persons, these needs may not become known. From an evaluation perspective, in this era of fiscal and performance accountability, it makes sense to document the long-term impact of vocational and transition services on participants. These results can be used to support the effectiveness of the program of services and to identify weaknesses in the program, which would guide revision efforts.

Conducting long-term follow-up of program leavers is difficult and somewhat outside of the training and skills of the typical service provider. The following discussion addresses the main points for consideration. Interested readers are referred to more detailed references for additional guidance (DeStefano \& Wagner, 1992; Dillman, 1978; Edgar, 1985; Fairweather 1984; Halpern, 1990; Menhard, 1990).

First, we believe a prospective, or follow-along approach, is the best way to track program leavers. In this approach, leavers are to be contacted at set time periods after leaving the program (e.g., every 3 months) and data are to be gathered, focusing on the individual's experiences over that period. This approach is advantageous because (a) it yields a higher response from leavers, as they tend to continue their association with the project through the contacts; (b) responses from the leavers do not rely on recalling previous experiences and are more accurate; (c) data collection becomes a regular and central part of the service delivery process; and (d) as data are gathered and analyzed regularly, results can be used to refine and improve the program and provide support services to leavers on an ongoing basis.

Second, one staff person (e.g., an administrative assistant) can be assigned to data collection efforts or data collection can be a responsibility of the transition staff. We have used both approaches and have found both to be acceptable in different projects. The main advantage of assigning a single person the responsibility of tracking program leavers is that this underscores the importance of gathering these data and this work is more likely to be completed. Further, this assignment allows that individual to become skilled at the data-collection procedures, assigning more objectivity and accuracy to the results.

Conversely the major advantage of having the transition staff be responsible for data collection is that the activities become ingrained in service delivery. That is, if the staff is assigned to track the individuals with whom they work after those persons leave the program, there is a logical and, hopefully, close connection between the staff person and the participant. This connection should foster awareness of the participant's location - or at least how or where to find him or her-and rapport in the exchange. Also, as one of the goals of the longitudinal data collection is to provide longterm support and to structure services to address participants' current needs, the transition specialist would seem the most logical person to perform these functions.

Third, it is important to gather long-term data on all leavers, even those with minimal association with the program. A fundamental assumption of this type of service delivery is that by affording these services, individuals who receive the services will do "better"-i.e., demonstrate better transition outcomes-than individuals who do not receive the services. A variation on this assumption is that individuals who receive more services or who receive services for a longer time, should do "better" than those who receive fewer services or who are not served as long. This assumption can be tested only by including all leavers and by specifying either the length of time individuals were in the program or whether they left the program successfully (e.g., completed their PFP, completed school, had paid employment).

Fourth, we have used and recommend phone calls as the way to gather these types of data. Phone interviews, in which a staff member administers the interview to the leaver over the phone, have the advantage of personal contact (i.e., because in the personal exchange it is possible to clarify questions and responses). Also, phone interviews are cheap, safe, and easy to schedule and conduct because the staff can complete them in the safety of the office or home and at various times (e.g., in the evening, on weekends), and the interviews tend to yield data of a quality equivalent to that from a personal interview. Moreover, phone interviews are minimally disruptive, and the staff has accepted them as part of the service delivery process.

Phone contacts should be structured according to a short script that presents written questions and response options. As a rule, these interviews should be short (10-15 minutes) and questions should be directed to employment, education (including postsecondary education), independent living, and social experiences (including arrest and mental health status) outcome areas. Questions also should be asked about the number and type of services the individual is receiving from community-based social service agencies. Finally, open-ended questions, in which the individual is allowed to comment in an unstructured manner rather than "yes" or "no" should be provided at the end of the interview to gather data that falls outside the structured questions.

Program staff will use this data to guide program changes, whereas administrators may examine the program's effectiveness (e.g., end of the fiscal year) or as the basis for making budgetary decisions. The results should be presented simply and clearly, as they provide a unique snapshot of the true "products" of the vocational and transition program. Moreover, review of these data and construction of these reports forces the program staff to examine its own work and its effects. 


\section{SUMMARY AND FUTURE DIRECTIONS}

Transition services for this population require intense service coordination and commitment to address the many individual and systems challenges. Daily time and effort are necessary to provide effective services to most youth and young adults with EBD. When provided this extensive support, most participants in Job Designs and RENEW made impressive progress on their educational and vocational goals, and we were impressed with the depth of their relationships with the project staff with whom they worked. We also believe that the transition services that these projects provided should be judged as successful and certainly worthy of continuation and replication in other sites. In line with this sentiment, we have identified several overriding impressions from our experiences, and we provide a brief discussion of issues that have to be addressed in future research or program development work.

First, the broad descriptor "EBD" really does not convey the magnitude or varied nature of this condition. These youth and young adults have multiple needs requiring specialized services and treatment that are simply beyond the purview and capabilities of a singular school transition program. This means that transition programs for this population should not and cannot be developed from the perspective of only one service agency, whether that be the public schools, mental health, or rehabilitation. To serve these people appropriately and effectively, a network of services from different agencies has to be developed and offered to these individuals.

This effort involves both system-level commitments and person-level service delivery decisions. By involving multiple agencies, the goal should be to decrease the service delays and bureaucratic entanglements that occur when there is no single point of contact in a service-centered system. Interagency connections and coordination, which are painstaking and time consuming to foster and construct, are essential in providing integrated and informed services to individuals. With this connection formed, a common forum for exchanging information on the strengths and weaknesses of these partnerships is critical to the ongoing development of the system, as well as to the efficiency and effectiveness of services.

Second, the amount of time necessary for the transition staff to address the multiple service needs cannot be underestimated. It is counter-productive to imagine providing the types of services we described in this article with staff-toparticipant ratios higher than $1: 12$ or 1:15. A service delivery structure with this ratio admittedly is more expensive than options with higher ratios. At the same time, we must state that it may be possible to offer different types, levels, and intensities of services to different types of adolescents and young adults with EBD and achieve similar successes. This issue relates to the necessary "dose" of services. If interventions can be tailored in this manner, service programs such as these could become more cost-efficient and effective.

To begin the effort, it is essential to study ways to measure and quantify the type and extent of the services provided and begin examining the relationships of those services to program outcomes. Even though the accurate empirical description of interventions in the social sciences is extremely difficult (Yeaton \& Sechrest, 1981), it is important so inferences can be drawn about which program components are effective and which are not.

Third, although we have been pleased with the results of these two projects, we also believe that the types of services we have described may have to be offered longer-term than we have been able to do within the 3- or 4-year grant periods we have had the opportunity to work within. In many instances those with whom we have worked need continued personal, agency, and community support to sustain the benefits of services they received. Others may not be able to benefit maximally from these types of services until later in their lives.

The projects described did not "cure" any of these youths and young adults. The diagnoses and disorders they carry are extremely durable and defy many of the intervention efforts provided (Kazdin, 1987a, 1987b; Wolf et al., 1987). Thus, we must consider this type of service delivery from a long-range perspective. The long range perspective results in more expensive programs and provisions-a recommendation not readily welcomed in this era of fiscal austerity despite the clear need and number of individuals who would benefit from these services. Accordingly, pressure will have to be brought to bear on key decision-makers from advocacy and family organizations to effect the system-wide change we believe is necessary.

We hypothesized-and some of our initial findings suggest-that the costs of intensive, interagency transition programs are offset by the wages participants receive and the related reductions in social service costs when youth and young adults are not referred to residential programs or incarcerated (Cheney et al., 1998). This contention deserves further analyses through studies of individuals who receive intensive, community-based interagency transition programs and have successful educational and vocational outcomes compared to young adults who don't achieve positive outcomes.

In closing, adolescents and young adults with EBD do not have to face a "cold world" in their transition to adult life. Our projects suggest that many adolescents and young adults with EBD can become contributing and successful members of society when they receive appropriate services. 
To believe that such success will be achieved easily or quickly would be naive, however. Programs such as Job Designs and RENEW have an important place in the service delivery milieu for this population. We hope that this article will prompt the development of other, similar programs and in some way improve the lives of these persons.

\section{REFERENCES}

Achenbach, T. (1966). The classification of children's psychiatric syndromes: A factor analytic study. Psychological Monographs, 80, 1-37.

Achenbach, T. (1990). Conceptualization of developmental psychopathology. In M. Lewis \& S. Miller (Eds.), Handbook of developmental psychopathology (pp. 3-14). New York: Plenum Press.

Achenbach, T., \& McConaughy, S. (1987). Empirically based assessment of child and adolescent psychopathology. Beverly Hills, CA: Sage.

Albee, G. (1982). Preventing psychopathology and promoting human potential. American Psychologist, 37, 1043-1050.

American Psychiatric Association. (1994). Diagnostic and statistical manual of mental disorders (4th ed). Washington, DC: Author.

Anthony W. (1979). Principles of psychiatric rehabilitation. Baltimore: University Park Press.

Azrin, N., \& Besalel, V. (1980). Job club counselor's manual. Baltimore: University Park Press.

Benz, M. R., \& Halpern, A.S. (1993). Vocational and transition services needed and received by students with disabilities during their last year of high school. Career Development for Exceptional Individuals, 16, 197-211.

Benz, M. R., \& Lindstrom, L. E. (1997). Building school-to-work programs: Strategies for youth with special needs. Austin, TX: PRO-ED.

Benz, M., Yovanoff, P., \& Doren, B. (1997). School-to-work components that predict postschool success for students with and without disabilities. Exceptional Children, 63, 151-165.

Blackorby, J., Edgar, E., \& Kortering, L. (1991). A third of our youth? A look at the problem of high school dropouts among students with mild handicaps. Journal of Special Education, 25, 102-113.

Blackorby, J. \& Wagner, M. (1996). Longitudinal postschool outcomes of youth with disabilities: Findings from the National Longitudinal Transition Study. Exceptional Children, 62, 399-413.

Bullis, M. (1992). Project SERVE: Support for the emotional, residential, vocational, and educational needs of young adults with emotional disorders. Washington, DC: Rehabilitation Services Administration, Nondirected Special Projects.

Bullis, M. (1995a). Achieving rehabilitation, independent living, and employment success for adolescents and young adults with serious emotional disorders and severe mental illness. Rehabilitation Services Administration, Directed Competition on the Community Transition of Persons with Serious Emotional Disorders/Severe Mental Illnesses.

Bullis, M. (1995b). Examination of the effect of vocational placements and service management on the development and continuation of serious emotional disturbances with adolescents with emotional and behavioral problems. Office of Special Education Programs, Directed Competition on the Prevention of Serious Emotional Disturbance.

Bullis, M., Bull, B., Johnson, P., \& Johnson, B. (1994). Identifying and assessing the community-based social behaviors of adolescents and young adults with emotional and behavioral disorders. Journal of Emotional \& Behavioral Disorders, 2, 173-189.

Bullis, M., \& Clark, H. B. (in press). Community life skills development: The role of the transition coach. In H. B. Clark \& M. Davis (Eds.), Transition of youth and young adults with emotional/behavioral disturbances into adulthood: Handbook for practitioners, parents, and policy makers. Baltimore: Paul H. Brookes.

Bullis, M., \& Davis, C. (Eds.). (in press). Functional assessment procedures in transition and rehabilitation for adolescents and adults with learning disorders. Austin, TX: Pro-Ed.
Bullis, M., \& Fredericks, H. D. (Eds.). (in press). Providing effective vocational/transition services to adolescents with emotional and behavioral disorders. Arden Hills, MN: Behavioral Institute for Children and Adolescents.

Bullis, M., Fredericks, H. D., Lehman, C., Paris, K., Corbitt, J., \& Johnson, B. (1994). Description and evaluation of the Job Designs program for adolescents with emotional or behavioral disorders. Behavioral Disorders, 19, 254-268.

Bullis, M., \& Gaylord-Ross, R. (1991). Moving on: Transitions for youth with behavioral disorders, R. Rutherford \& L. Bullock, Series Eds. Reston, VA: Council for Exceptional Children.

Bullis, M., Nishioka-Evans, V., Fredericks, H. D., \& Davis, C. (1993). Identifying and assessing the job-related social skills of adolescents and young adults with emotional and behavioral disorders. Journal of Emotional and Behavioral Disorders, 1, 236-250.

Bullis, M., \& Paris, K. (1995). Competitive employment and service management for adolescents and young adults with emotional and behavioral disorders. Special Services in the Schools, 10, 77-96.

Bullis, M., \& Walker, H. (1995). Characteristics and causal factors of troubled youth. In C. M. Nelson, B. Wolford, \& R. Rutherford (Eds.), Comprehensive and collaborative systems that work for troubled youth: A national agenda (pp.15-28). Richmond, KY: Eastern Kentucky University National Coalition for Juvenile Justice Services, Training Resource Center.

Burns, B., Hoagwood, K., \& Maultab, K. (1998). Improving outcomes for children and adolescents with serious emotional and behavioral disorders: Current and future directions. In Epstein, M., Kutash, K., \& Duchnowski, A. (Eds). Outcomes for children and youth with behavioral and emotional disorders and their families (pp. 685-708). Austin, TX: Pro-Ed.

Carson, R., Sitlington, P., \& Frank, A. (1995). Young adulthood for individuals with behavior disorders: What does it hold? Behavioral Disorders, 20, 127-135.

Chamberlin, P. (1992). Comparative evaluation of specialized foster care for seriously delinquent youth: A first step. Eugene: Oregon Social Learning Center.

Chadsey-Rusch, J. (1986). Identifying and teaching valued social behaviors. In F. Rusch (Ed.), Competitive employment: Issues and strategies (pp. 273-289). Baltimore: Paul H. Brookes.

Chadsey-Rusch, J. (1990). Teaching social skills on the job. In F. Rusch (Ed.), Supported employment: Models, methods, and issues (pp. 161-180). Sycamore, IL: Sycamore Press.

Cheney, D., Hagner, D., Malloy, J., Cormier, G., \& Bernstein, S. (1998). Transition services for youth and young adults with emotional disturbance: Description and initial results of project RENEW. Career Development for Exceptional Individuals, 21, 17-32.

Cheney, D., Malloy, J., \& Hagner, D. (1998). Finishing high school in many different ways: Project RENEW in Manchester, New Hampshire. Effective School Practices, 17(2), 43-52.

Cheney, D., Rodriguez, E., \& Martin, J. (in press). Secondary and postsecondary education of young adults with emotional and behavioral difficulties. In H. B. Clark \& M. Davis Eds., Transition of youth and young adults with emotional/behavioral disturbances into adulthood: Handbook for practitioners, parents, and policy makers. Baltimore: Paul H Brookes.

Clark, H. B. (1998). Transition to independence process: TIP operations manual. Tampa: University of South Florida. Florida Mental Health Institute.

Cobb, B., \& Lakin, D. (1985). Assessment and placement of handicapped pupils into secondary vocational education programs. Focus on Exceptional Children, 17(7), 1-14.

Cohen, B., \& Anthony, W. (1984). Functional assessment in psychiatric rehabilitation. In A. Halpern \& M. Fuhrer (Eds.), Functional assessment in rehabilitation (pp. 79-100). Baltimore: Paul Brookes.

Council for Children With Behavioral Disorders. (1989). Position paper on the provision of service to children with conduct disorders. Behavioral Disorders, 15, 180-189. 
Council for Exceptional Children. (1998). CEC's comments on the proposed IDEA regulations: Letter sent to the Office of Special Education Programs and Rehabilitative Services. Reston, VA: Author.

Crites, J. (1989). Career development in adolescence: Theory, measurement, and longitudinal findings. In D. Stern \& D. Eichorn (Eds.), Adolescence and work: Influences of social structure, labor markets, and culture (pp. 141-158). Hillsdale, NJ: Lawrence Earlbaum.

Cullinan, D., Epstein, M., \& McLinden, D. (1986). Status and change in state administrative definitions of behavior disorders. School Psychology Review, 15, 383-392.

Cullinan, D., Epstein, M., \& Sabornie, E. (1992). Selected characteristics of a national sample of seriously emotionally disturbed adolescents. Behavioral Disorders, 17, 273-280.

D'Amico, R., \& Blackorby, J. (1992). Trends in employment among outof-school youth with disabilities. In $M$. Wagner, $R$. D'Amico, C. Marder, L. Newman, \& J. Blackorby (Eds.), What happens next? Trends in postschool outcomes of youth with disabilities (pp. 4-1 4-47). Menlo Park, CA: SRI International.

DeStefano, L., \& Wagner, M. (1992). Outcome assessment in special education: What lessons have we learned? In F. Rusch, L. DeStefano, J. Chadsey-Rusch, L. Phelps, \& E. Szymanski (Eds.), Transition from school to adult life (pp. 173-207). Sycamore, IL: Sycamore Publishing.

Dillman, D. (1978). Mail and telephone surveys. New York: John Wiley.

Dodge, K., Price, J., Bachorowski, J., \& Newman, J. (1990). Hostile attributional biases in severely aggressive adolescents. Journal of Abnormal Psychology, 99, 385-392.

Dodge, K. A., \& Murphy, R. R. (1984). The assessment of social competence in adolescents. In P. Karoly \& J. J. Steffen (Eds.), Adolescent behavior disorders: Foundations and contemporary concerns (Vol. 3, pp. 61-96). Lexington, MA: Lexington Books.

Donovan, J., \& Jessor, R. (1985). Structure of problem behavior in adolescence and young adulthood. Journal of Consulting \& Clinical Psychology, 53, 890-904.

Doren, B. (1992). Social problems of adolescents with disabilities in transition. Eugene: University of Oregon, Secondary and Transition Programs.

Doren, B., Bullis, M., \& Benz, M. (1996a). Predicting the arrest status of adolescents with disabilities in transition. The Journal of Special Education, 29, 363-380.

Doren, B., Bullis, M., \& Benz, M. (1996b). Predicting the victimization status of adolescents with disabilities in transition. Exceptional Children, 63, 7-18.

Dryfoos, J. (1990). Adolescents at risk. New York: Oxford University Press.

D’Zurilla, T. J. (1986). Problem solving therapy: A social competence approach to clinical intervention. New York: Springer.

D'Zurilla, T., \& Goldfried, M. (1971). Problem solving and behavior modification. Journal of Abnormal Psychology, 78, 107-126.

Eber, L. (1996). Restructuring schools through the wraparound approach: The LADSE experiences. In R. J. Illback \& C. Michael Nelson (Eds.) Emerging school-based approaches for children with emotional and behavioral problems: Research and practice in service integration (pp. 135-150). New York: Haworth Press.

Eber, L. (1994, March). Bringing the wraparound approach to school: A model for inclusion. Paper presented at meeting of Research Conference for Children's Mental Health, Tampa, FL.

Eber, L., Nelson, C. M., Miles, P. (1997). School-based wraparound for students with emotional and behavioral challenges. Exceptional Children, 63, 539-555.

Edgar, E. (1985). How do special education students fare after they leave school? Exceptional Children, 51, 470-473.

Edgar, E. (1987). Secondary programs in special education: Are many of them justifiable? Exceptional Children, 53, 555-561.

Edgar, E. (1988). Employment as an outcome for mildly handicapped students: Current status and future directions. Focus on Exceptional Children, 21(1), 1-8.
Edgar, E., \& Levine, P. (1987). Special education students in transition: Washington state data 1976-1986. Seattle: University of Washington, Experimental Education Unit.

Elam, S., Rose, L., \& Gallup, A. (1994). The 26th annual Phi Delta Kappan Gallup poll of the public's attitudes toward the public schools. $P h i$ Delta Kappan, 26, 42-56.

Everson, J. M. (1993). Youth with disabilities: Strategies for interagency transition programs. Boston: Andover Medical Publishers.

Fairweather, J. (1984). Alternative study designs and revised conceptual framework for the longitudinal study of handicapped youth in transition. Menlo Park, CA: SRI International.

Forness, S., \& Kavale, K. (1993). The balkanization of special education: Proliferation of categories and subcategories for "new" disorders. In J. Marr, G. Sugai, \& G. Tindal (Eds.), The Oregon conference monograph ( $\mathrm{pp} . \mathrm{ix}-\mathrm{xv})$. Eugene: University of Oregon, College of Education.

Forness, S., \& Knitzer, J. (1992). A new proposed definition and terminology to replace "serious emotional disturbance" in the Individuals with Disabilities Education Act. School Psychology Review, 21, $12-20$.

Frank, A. R., Sitlington, P. L., \& Carson, R. (1991). Transition of adolescents with behavioral disorders-Is it successful? Behavioral Disorders, 16, 180-191.

Fredericks, H. D., \& Bullis, M. (1989). Community-based supported work program for adolescents with emotional and behavioral disorders. Washington, DC: Rehabilitation Services Administration, Directed Competition on Model Development in Supported Employment.

Frey, W. (1984). Functional assessment in the 80s. In A. Halpern \& M. Fuhrer (Eds.), Functional assessment in rehabilitation (pp. 11-44). Baltimore: Paul H. Brookes.

Garrett, C. (1985). Effects of residential treatment on adjudicated delinquents: A meta-analysis. Journal of Research on Crime \& Delinquency, 22, 287-308.

Goldstein, A., Glick, B., Irwin, M., Pask-McCartney, C., \& Rubama, I. (1989). Reducing delinquency: Intervention in the community. Elmsford, NY: Pergamon Press.

Goldstein, A., Harootunian, B., \& Conoley, J. (1993). Student aggression. New York: Guilford Press.

Goldstein, A., Sprafkin, R., Gershaw, N., \& Klein, P. (1980). Skillstreaming the adolescent. Champaign, IL: Research Press.

Hagner, D., Cheney, D., \& Malloy, J. (in press). Career-related outcomes of a model transition demonstration for young adults with emotional disturbance. Rehabilitation Counseling Bulletin.

Hallahan, D., \& Kauffman, J. (1977). Categories, labels, behavioral characteristics: ED, LD, and EMR reconsidered. Journal of Special Education, 11, 139-149.

Halpern, A. (1985). Transition: A look at the foundations. Exceptional Children, 51, 479-486.

Halpern, A. (1990). A methodological review of follow-up and followalong studies tracking school leavers from special education. Career Development for Exceptional Individuals, 13, 13-27.

Halpern, A. (1993). Quality of life as a conceptual framework for evaluating transition outcomes. Exceptional Children, 59, 486-498.

Halpern, A. (1994). The transition of youth with disabilities to adult life: A position statement of the Division on Career Development and Transition. Career Development for Exceptional Individuals, 17, 115-124.

Halpern, A., Doren, B., \& Benz, M. (1993). Job experiences of students with disabilities in their last two years in school. Career Development for Exceptional Individuals, 16, 63-74.

Halpern, A., \& Fuhrer, M. (Eds.). (1984). Functional assessment in rehabilitation. Baltimore: Paul H. Brookes.

Hasazi, S. B., Gordon, L. R., \& Roe, C. (1985). Factors associated with the employment status of handicapped youth exiting high school from 1979 to 1983. Exceptional Children, 51, 455-469.

Hazel, J. S., \& Schumaker, J. B. (1988). Social skills and learning disabilities: Current issues and recommendations for future research. In J. 
Kavanagh, \& T. Truss (Eds.), Learning disabilities: Proceedings of the national conference (pp. 293-343). Parkton, MD: York Press.

Hazel, J. S., Schumaker, J. B., Sherman, J., \& Sheldon-Wildgen, J. (1981). The development and evaluation of a group skills training program for court-adjudicated youth. In D. Upper \& S. Ross (Eds.), Behavioral group therapy (pp. 113-152). Champaign, IL: Research Press.

Hazel, J. S., Schumaker, J. B., Sherman, J. A., \& Sheldon-Wildgen, J. (1982). Group social skills training: A program for court-adjudicated probationary youth. Criminal Justice \& Behavior, 9, 35-53.

Hobbs, N., \& Robinson, S. (1982). Adolescent development and public policy. American Psychologist, 37, 212-223.

Hursh, N., \& Kerns, A. (1988). Vocational evaluation in special education. Boston: College-Hill.

Kauffman, J. (1988). Characteristics of children's behavior disorders (4th ed.). Columbus, $\mathrm{OH}$ : Charles E. Merrill.

Kavale, K., Forness, S., \& Alper, A. (1986). Research in behavioral disorders/emotional disturbance: A survey of subject identification criteria. Behavioral Disorders, 11, 159-167.

Kazdin, A. (1987a). Conduct disorders in childhood and adolescence. Beverly Hills, CA: Sage.

Kazdin, A. (1987b). Treatment of antisocial behavior in children: Current status and future directions. Psychological Bulletin, 102, 187-203.

Kazdin, A. (1993). Adolescent mental health: Prevention and treatment programs. American Psychologist, 48, 127-141.

Kelly, J. (1982). Social skills training. New York: Springer.

Kelley, E. (1986). Issues, procedures, and criteria in discriminating SED from conduct disordered students. Presentation at the Oregon Association of School Psychology, Lincoln City.

Knitzer, J. (1993). Children's mental health policy: Challenging the future. Journal of Emotional \& Behavioral Disorders, 1, 8-16.

Knitzer, J., Steinberg, Z., Fleisch, B. (1990). At the schoolhouse door. New York: Bank Street College of Education.

Knowlton, H. E., \& Clark, G. (1987). Transition issues for the 1990s. Exceptional Children, 53, 562-563.

Kohler, P. (1993). Best practices in transition: Substantiated or implied? Career Development for Exceptional Individuals, 16, 107-121.

Koop, C. E., \& Lundberg, G. (1992). Violence in America: A public health emergency: Time to bite the bullet back. Journal of the American Medical Association, 267, 3075-3076.

Kortering, L., \& Blackorby, J. (1992). High school dropout and students identified with behavioral disorders. Behavioral Disorders, 18, 24-32.

Kortering, L. J., \& Edgar, E. B. (1988). Vocational rehabilitation and special education: A need for cooperation. Rehabilitation Counseling Bulletin, 31, 178-184

Kozleski, E., Cessna, K., Bechard, S., \& Borock, J. (1993). Lessons from policy decisions: Politics and services for students with emotional and behavioral disorders. Behavioral Disorders, 18, 205-217.

Lichtenstein, S. \& Nisbet, J. (1992). From school to adult life: Young adults in transition. A national and state overview. In S. Lichtenstein (Ed.) A compendium of research and evaluation in secondary special education, transition, and related topics. Durham, NH: University of New Hampshire.

Louri, I. (1994). Principles of local system development for children, adolescents and their families. Chicago: Kaleidoscope.

Lourie, I., Stroul, B., \& Friedman, R. (1998). Community-based systems of care: From advocacy to outcomes. In M. Epstein, M., K. Kutash, \& A. Duchnowski (Eds.). Outcomes for Children and Youth with behavioral and emotional disorders and their families (pps. 3-20). Austin, TX: ProEd.

Maag, J., \& Howell, K. (1991). Serving troubled youth or a troubled society? Exceptional Children, 58, 74-76.

MacMillan, D., \& Kavale, K. (1986). Educational interventions. In H. Quay \& J. Werry (Eds.), Psychopathological disorders of childhood (3d ed., pp. 583-621). New York: John Wiley \& Sons.

Malloy, J., Cheney, D., \& Cormier, G. (1998). Interagency collaboration and the transition to adulthood for students with emotional or behavioral disabilities. Education \& Treatment of Children, 21, 303-320.
Malloy, J., Cheney, D., Hagner, D., Cormier, G., \& Bernstein, S. (1998). Personal futures planning for youth and young adults with emotional and behavioral disorders. Reaching Today's Youth, 2, 2-30.

Malmgren, K., Neel, R. \& Edgar, E., (1998). Postschool status of youths with behavioral disorders. Behavioral Disorders, 23, 257-263.

Marder, C. (1992b). Education after secondary school. In M. Wagner, R. D'Amico, C. Marder, L. Newman, \& J. Blackorby (Eds.), What happens next? Trends in postschool outcomes of youth with disabilities (pp. 3-1 - 3-39). Menlo Park, CA: SRI International.

Marder, C. (1992a). Secondary students classified as seriously emotionally disturbed: How are they being served? Menlo Park, CA: SRI International.

Marder, C. Wechsler, M., \& Valdes, K. (1993). Services for youth with disabilities after secondary school. Menlo Park, CA: SRI International.

Martin, J. E. \& Marshall, L. H. (1996), ChoiceMaker: Infusing self-determination instruction into the IEP and transition process. In J.D. Sands \& M.L. Wehmeyer (Eds.), Self determination across the life span: Independence and choice for people with disabilities (pp. 211-232). Baltimore: Paul H. Brookes.

Massimo, J., \& Shore, M. (1963). The effectiveness of a vocationally oriented psychotherapeutic program for adolescent delinquent boys. American Journal of Orthopsychiatry, 4, 634-642.

McClelland, D. (1973). Testing for competence rather than for "intelligence." American Psychologist, 28, 1-14.

McFall, R. (1982). A review and reformulation of the concept of social skills. Behavioral Assessment, 4, 1-33.

Menhard, S. (1990). Longitudinal research. Newbury Park, CA: Sage.

National Institute on Drug Abuse. (1988). National household survey on drug abuse. Washington, DC: U.S. Government Printing Office.

National School Boards Association. (1993, November 5). Letter to Dr. Tom Hehir in opposition to the adoption of the term emotional/ behavioral disorder. Alexandria, VA: National School Boards Association.

Neel, R., Meadow, N., Levine, P., \& Edgar, E. (1988). What happens after special education: A statewide follow-up study of secondary students who have behavioral disorders. Behavioral Disorders, 13, 209-216.

Nelson, C. M., Center, D., Rutherford, R. B., \& Walker, H. M. (1991). Serving troubled youth in a troubled society: A reply to Maag and Howell. Exceptional Children, 58, 77-79.

Nelson, C. M. \& Pearson, C A. (1991). Integrating services for children and youth with emotional or behavioral disorders. Reston, VA: The Council for Exceptional Children.

Newman, L. (1992). A place to call home: Residential arrangements of outof-school youth with disabilities. In M. Wagner, R. D'Amico, C. Marder, L. Newman, \& J. Blackorby (Eds.), What happens next? Trends in postschool outcomes of youth with disabilities (pp. 5-1 5-35). Menlo Park, CA: SRI International.

Nisbet, J. (Ed.). (1992). Natural supports in school, at work, and in the community for people with severe disabilities. Baltimore: Paul Brooks.

Nishioka, V. (in press). Vocational support groups. In M. Bullis \& H. D. Fredericks, (Eds.), Providing effective vocational/transition services to adolescents with emotional and behavioral disorders. Arden Hills, MN: Behavioral Institute for Children and Adolescents.

O’Brien, J., \& Forest, M., with Snow, J. \& Hasbury, D. (1987). Action for inclusion. Toronto, Ontario, Canada: Frontier College Press.

Parker, J., \& Asher, S. (1987). Peer relations and later personal adjustment: Are low-accepted children at risk? Psychological Bulletin, 102, 357-389.

Patterson, G. R., Reid, J., \& Dishion, T. (1992). Antisocial boys. Eugene, OR: Castalia.

Platt, J. J., Scura, W. C., \& Hannon, J. R. (1973). Problem-solving thinking of youthful incarcerated heroin addicts. Journal of Community Psychology, 1, 278-281.

Platt, J. J., Spivack, G., Altman, N., Altman, D., \& Peizer, S. B. (1974). Adolescent problem-solving thinking. Journal of Consulting \& Clinical Psychology, 42, 787-793.

Quay, H. (Ed.). (1986). Handbook of juvenile delinquency. New York: John Wiley. 
Rutherford, R., Bullis, M., Wheeler Anderson, C., \& Griller, H. (In press). Youth with special education disabilities in the correctional system: Prevalence rates and identification issues (Invited monograph). Washington, DC: Office of Juvenile Justice and Prevention and Office of Special Education Programs.

Sacks, S. Z., Hirsch, M., Tierney-Russell, D., \& Gaylord-Ross, R. (Eds). (1992). The status of social skills training in special education and rehabilitation: Present and future trends. Nashville, TN: Vanderbilt University.

Shore, M. F., Massimo, J. L., \& Mack, R. (1965). Changes in the perception of interpersonal relationships in successfully treated adolescent delinquent boys. Journal of Consulting Psychology, 29(3), 213-217.

Singer, S. (1987). Victims in a birth cohort. In M. Wolfgang, T. Thornberry, \& R. Figilo, From boy to man, from delinquency to crime (pp. 163-179). Chicago: University of Chicago Press.

Sitlington, P., Clark, G., Brolin, D., \& Vacanti, J. (1985). Career/vocational assessment in the public school setting: The position of the Division on Career Development. Career Development for Exceptional Individuals, 8, 3-6.

Sitlington, P., Frank, A., \& Carson, R. (1993). Adult adjustment among high school graduates with mild disabilities. Exceptional Children, 59, 221-233.

Skiba, R., Polsgrove, L., \& Nasstrom, K. (1996). Developing a system of care: Interagency collaboration for students with emotional/behavioral disorders. Reston, VA: Council for Exceptional Children.

Spivack, G., Platt, J., \& Shure, M. (1976). The problem solving approach to adjustment. San Francisco: Josey-Bass.

Steinberg, L., Greenberger, E., Garduque, L., Ruggerio, M., \& Vaux, A. (1982). Effects of working on adolescent development. Developmental Psychology, 18, 385-395

Steinberg, M., \& Dodge, K. (1983). Attributional bias in aggressive adolescent boys and girls. Journal of Social \& Clinical Psychology, 1, 312-321.

Stern, D., \& Eichorn, D. (Eds.). (1989). Adolescence and work: Influences of social structure, labor markets, and culture. Hillsdale, NJ: Lawrence Earlbaum.

Stroul, B. A. (1993). System of care for children and adolescents with severe emotional disturbances: What are the results? Washington, DC: Child and Adolescent Service System Program, Technical Assistance Center, Georgetown University. (ERIC Document No. ED 364 025)

Stroul, B. A., \& Friedman, R. M. (1986). A system of care for severely emotionally disturbed children and youth. Washington, D. C.: Child and Adolescent Service System Program Technical Assistance Center, Georgetown University. (ERIC Document No. ED 330 167).

Szymanski, E. (1994). Transition: Life-span and life-space considerations for empowerment. Exceptional Children, 60, 402-410.

Thornton, H., \& Zigmond, N. (1987). Predictors of dropout and unemployment among LD high school youth: The holding power of secondary vocational education for $L D$ students. Pittsburgh: University of Pittsburgh.

Thornton, H., \& Zigmond, N. (1988). Secondary vocational training for LD students and its relationship to school completion status and post school outcomes. Illinois Schools Journal, 67(2), 37-54.

Trower, P., Bryant, B., \& Argyle, M. (1978). Social skills and mental health. London: Methuen.

Valdes, K., Williamson, C., \& Wagner, M. (1990). The national longitudinal transition study of special education students: Vol. 3. Youth categorized as emotionally disturbed. Palo Alto, CA: SRI International.
Vandercook, T., York, J., \& Forest, M. (1989). The McGill action planning system (MAPS): A strategy for building the vision. Journal of the Association for Persons with Severe Handicaps, 14, 205-215.

Wagner, M. (1991). The benefits associated with secondary vocational education for young people with disabilities. Menlo Park, CA: SRI International.

Wagner, M. (1992a). "A little help from my friends": The social involvement of young people with disabilities. In M. Wagner, R. D' Amico, C. Marder, L. Newman, \& J. Blackorby (Eds.), What happens next? Trends in postschool outcomes of youth with disabilities (pp. 6-1 6-43). Menlo Park, CA: SRI International.

Wagner, M. (1992b). Analytic overview: NLTS design and longitudinal analysis approach. In M. Wagner, R. D'Amico, C. Marder, L. Newman, \& J. Blackorby (Eds.), Trends in postschool outcomes of youth with disabilities (pp. 2-1 to 2-14). Menlo Park, CA: SRI International.

Wagner, M., Blackorby, J., Cameto, R., \& Newman, L. (1993). What makes a difference? Influences on postschool outcomes of youth with disabilities. Menlo Park, CA: SRI International.

Wagner, M., \& Shaver, D. (1989). Educational programs and achievements of secondary special education students: Findings from the National Longitudinal Transition Study. Menlo Park, CA: SRI International.

Walker, H. M., \& Bullis, M. (1991). Behavior disorders and the social context of regular class integration: A conceptual dilemma? In J. Lloyd, A. Repp, \& N. Singh (Eds.), The Regular education initiative: Alternative perspectives on concepts, issues, and models (pp.75-94). Sycamore, IL: Sycamore Press.

Walker, H., Colvin, G., \& Ramsey, E. (1995). Antisocial behavior in schools: Strategies and best practices. Pacific Grove, CA: Brooks/ Cole.

Weber, J. (1987). Strengthening vocational education's role in decreasing the dropout rate. Columbus, $\mathrm{OH}$ : Ohio State University, Center for Research in Vocational Education.

Wehmeyer, M. L. (1998). Student Involvement in transition-planning and transition-program implementation. In F. Rusch \& J. Chadsey (Eds.), Beyond High School: Transition from school to work (pp. 206-233).

Will, M. (1984). OSERS program for the transition of youth with disabilities: Bridges from school to working life. Washington, DC: Office of Special Education and Rehabilitation.

William T. Grant Foundation. (1988). The forgotten half: Non-college youth in America. Author: Washington, DC.

Wolf, M., Braukmann, C., \& Ramp, K. (1987). Serious delinquent behavior as a part of a significantly handicapping condition: Cures and supportive environments. Journal of Applied Behavior Analysis, 20, 347-359.

Yeaton, W., \& Sechrest, L. (1981). Critical dimensions in the choice and maintenance of successful treatments: Strength, integrity, and effectiveness. Journal of Consulting \& Clinical Psychology, 49, 156-167.

This article was prepared through grant funds awarded to the authors by the Rehabilitation Services Administration and by the Office of Special Education Programs. No endorsement of the views offered herein by those agencies should be inferred.

\section{PERMISSIONS AND COPYRIGHT}

All rights are reserved. No part of this publication may be reproduced, photocopied, faxed, stored in a retrieval system, or transmitted in any form or by any means, electronic, mechanical, recording or otherwise, without the prior written permission of the publisher.
Back issues are available for sale. Reproduction requires permission and payment of fees. It is illegal and a violation of federal copyright law to reproduce this publication without permission. Direct all inquiries to the permissions editor. 